\title{
A Review on Hemeoxygenase-2: Focus on Cellular Protection and Oxygen Response
}

\author{
Jorge Muñoz-Sánchez and María Elena Chánez-Cárdenas \\ Laboratorio de Patología Vascular Cerebral, Instituto Nacional de Neurología y Neurocirugía Manuel Velasco Suárez, \\ 14269 Delegación Tlalpan, DF, Mexico
}

Correspondence should be addressed to María Elena Chánez-Cárdenas; echanezc@gmail.com

Received 21 February 2014; Accepted 30 April 2014; Published 17 July 2014

Academic Editor: Syed Ali

Copyright ( 2014 J. Muñoz-Sánchez and M. E. Chánez-Cárdenas. This is an open access article distributed under the Creative Commons Attribution License, which permits unrestricted use, distribution, and reproduction in any medium, provided the original work is properly cited.

\begin{abstract}
Hemeoxygenase (HO) system is responsible for cellular heme degradation to biliverdin, iron, and carbon monoxide. Two isoforms have been reported to date. Homologous $\mathrm{HO}-1$ and $\mathrm{HO}-2$ are microsomal proteins with more than $45 \%$ residue identity, share a similar fold and catalyze the same reaction. However, important differences between isoforms also exist. HO-1 isoform has been extensively studied mainly by its ability to respond to cellular stresses such as hemin, nitric oxide donors, oxidative damage, hypoxia, hyperthermia, and heavy metals, between others. On the contrary, due to its apparently constitutive nature, HO-2 has been less studied. Nevertheless, its abundance in tissues such as testis, endothelial cells, and particularly in brain, has pointed the relevance of HO-2 function. HO-2 presents particular characteristics that made it a unique protein in the HO system. Since attractive results on $\mathrm{HO}-2$ have been arisen in later years, we focused this review in the second isoform. We summarize information on gene description, protein structure, and catalytic activity of HO-2 and particular facts such as its cellular impact and activity regulation. Finally, we call attention on the role of HO-2 in oxygen sensing, discussing proposed hypothesis on heme binding motifs and redox/thiol switches that participate in oxygen sensing as well as evidences of HO-2 response to hypoxia.
\end{abstract}

\section{Introduction}

The hemeoxygenase (HO) system is composed by microsomal enzymes (EC 1.14.99.3; heme-hydrogen donor-oxygen oxidoreductases) involved in the degradation of heme, a molecule with important roles in biological systems. The $\mathrm{HO}$ system regulates hemeprotein levels and protects cells from the deleterious effects of intracellular free heme [1-3]. In mammalian cells, two catalytically active hemeoxygenase isozymes are expressed: $\mathrm{HO}-1$ and $\mathrm{HO}-2$.

$\mathrm{HO}-1$ is a $32 \mathrm{kDa}$ member of the stress protein superfamily (HSP32). It has a broad spectrum of inducers $[4,5]$ and is abundant in spleen, liver, and bone marrow [6]. On the other hand, the $36 \mathrm{kDa} \mathrm{HO}-2$ does not respond to the numerous factors that induce HO-1. However, high expression of $\mathrm{HO}-$ 2 is observed in testis, brain, and endothelial and smooth cells from cerebral vessels [7-10]. HO-1 has been the focus of researchers for a long time. Several studies report that overexpression of HO-1 mediated by various stimuli provides antioxidant protection in a variety of cells and tissues [6]. Due to its ability to respond to several cellular stresses and the numerous evidences of cell and tissue protection as result of HO-1 induction in different models and pathologies it has been considered as an ideal cytoprotective enzyme. Actually, it has been suggested that modulation of HO-1 expression and activity could have a potential therapeutic value [11-15]. In contrast, $\mathrm{HO}-2$ due to its apparently constitutive role has been less studied. HO-2 has attracted the attention of several research groups since evidence obtained with genetically modified animals has revealed its protective relevance [1618]. Furthermore, it has been observed that the expression of HO-2 in in vivo and in vitro models is not strictly constitutive as always stated [19-21]. Emblematic reviews have been published about the HO system $[1,7,8,22-24]$ and numerous reviews exist on HO-1 suggesting its protective role ([11$15,25-28]$, between many others). However, our perception is 
that specific information about $\mathrm{HO}-2$ has been less attended or at least only included as part of the $\mathrm{HO}$ system. We consider that there is enough and relevant information on HO-2 specifically. In this review, after a brief description of $\mathrm{HO}$ system as the main detoxifying system of heme to establish its cellular and biological importance, we focused in literature about HO-2 gene, protein structure, and catalytic activity. Finally we summarize evidence about suggested functions of HO-2 such as its protective role in cellular damage and importantly in the role of HO-2 as an enzyme that participates in the regulation of $\mathrm{O}_{2}$ sensing system and its response in models that generate hypoxic stress.

\section{Heme and Its Degradation by the HO System}

Heme is an iron-protoporphyrin complex with essential roles in biological systems. It is an essential prosthetic group of enzymes with functions such as oxygen storage and transport (hemoglobin and myoglobin), electron transport and energy generation (NADPH oxidase, guanylyl cyclase and cytochrome P450 family); and enzymatic systems such as catalase, peroxidase, nitric oxide synthase (NOS), and cyclooxygenase [3]. Several pathological conditions have shown the damaging effects of free heme [29-31]. The excess of free heme provokes cell damage and tissue injury particularly when is released from intracellular hemeproteins. The extreme hydrophobicity of heme may promote deleterious iron-dependent reactions leading to reactive oxygen species (ROS) generation and membrane lipid peroxidation, disrupting cellular membranes of several organelles such as mitochondria, endoplasmic reticulum, nuclei, and cell membrane [32, 33]. The cellular free heme may increase after extracellular heme overload, increased heme synthesis, accelerated breakdown of heme proteins by a cellular stress, or impaired incorporation into apo-heme proteins resulting in increased levels of ROS and subsequently, oxidative damage and cellular injury [3,31]. Therefore, the levels of heme are tightly maintained and regulated by either synthesis or degradation mechanisms. In order to survive heme toxicity, cells have developed heme detoxification systems. In mammals, the main responsible to detoxify free heme is $\mathrm{HO}$ system, however Xanthine Oxidase and $\mathrm{H}_{2} \mathrm{O}_{2}$ plus NADPHcytochrome $\mathrm{P} 450$ reductase can also degrade the heme molecule [8]. There are also extra heme degrading systems such as hemopexin, the formation of heme and albumin complexes to prevent the presence of extracellular heme in blood plasma, the heme-scavenger function of Lipocalin alpha 1-microglobulin (alpha-1 m), reduced glutathione able to degrade heme, and heme binding proteins [3].

The cytoprotective role of $\mathrm{HO}$ system comprises the reduction of cellular free heme and the generation of metabolites during the catalytic reaction. $\mathrm{HO}$ isoenzymes are positioned within endoplasmic reticulum, and in conjunction with NADPH cytochrome P450 reductase, split the tetrapyrrole heme ring to biliverdin (BV), free ferrous iron $\left(\mathrm{Fe}^{2+}\right)$, and carbon monoxide (CO). BV is subsequently metabolized to bilirubin (BR) by Biliverdin Reductase (BVR) (Figure 1) [34].
Reaction starts with the formation of the ferric hemeHO complex. Ferric heme-iron is then reduced to a ferrous state by the first electron donated from NADPH by NADPH cytochrome $\mathrm{P} 450$ reductase. Molecular oxygen binds to the complex to form a metastable oxy-form and iron-bound oxygen is converted to a hydroperoxide intermediate $\left(\mathrm{Fe}^{3+}\right.$ $\mathrm{OOH}$ ), by receiving another electron from the NADPH cytochrome $\mathrm{P} 450$ reductase and a proton from the distal pocket water. Terminal oxygen of $\mathrm{Fe}^{3+}-\mathrm{OOH}$ attacks the $\alpha$ meso-carbon of the porphyrin ring to form ferric $\alpha$-mesohydroxyheme. This species of heme reacts with molecular oxygen and yields the ferrous verdoheme-HO complex and $\mathrm{CO}$. The oxy-verdoheme-HO complex is converted to ferric iron-biliverdin chelate via a hydroperoxide intermediate, which is still bound to HO protein. The iron of the ferric biliverdin is reduced to the ferrous state by the reductase in order to liberate $\mathrm{Fe}^{2+}$ and $\mathrm{BV}$ to complete the total $\mathrm{HO}$ reaction (Figure 2). In the in vitro reaction, the release of $\mathrm{BV}$ from the enzyme is the rate limiting step [35-37].

2.1. The Relevance of HO Catalytic Activity Products. All the products of HO activity are involved in physiological and pathophysiological processes including fundamental adaptive response to cellular stress, apoptosis, and inflammation [38-41] (Figure 1). The bile pigments BV and BR are powerful antioxidants which scavenge ROS and nitrogen reactive species through recycling mechanism between BR and BV [42]. In addition, BR inhibits the activity of NADPH oxidase [43] and the complement cascade at the C1 step in the Classical Pathway, suggesting that bile pigments could serve as endogenous tissue protectors through anticomplement actions [44]. It has been reported that BR suppresses the inflammatory response inhibiting IL-1 and IL-2 production, decreasing natural killer activity and antibody dependent cellular toxicity [45].

Several physiological roles for $\mathrm{CO}$, the other product of $\mathrm{HO}$ reaction, have been reported. One of them directly involve the modulation of guanylate cyclase with the resultant production of cyclic guanine monophosphate (cGMP) leading to vasodilation, neurotransmission, inhibition of platelet aggregation, and antiproliferative effects on smooth muscle [46]. CO also has shown anti-inflamatory, antiapoptotic, and antiproliferative effects through modulation of $\mathrm{p} 38 \beta$ and mitogen-activated protein kinase (MAPK) pathways [47-50]. A recent described role of $\mathrm{CO}$ is the cell protection by the stabilization of the hypoxia induced factor $1 \alpha$ (HIF- $1 \alpha)$ in macrophages as well as in tissues from ischemia-reperfusion injury [51]. Additionally, CO protective effects were observed in endothelial cells, macrophages, and vascular smooth muscle cells attributed to a decrease in ROS generation via inhibition of cytochromes on both NADPH oxidase and the respiratory chain [52]. Higher levels of CO also inhibit NOS reducing the production of peroxynitrite [46].

Finally, $\mathrm{Fe}^{2+}$ produced by $\mathrm{HO}$ activity is rapidly removed by ferritin, limiting its pro-oxidant capacity [53]. $\mathrm{Fe}^{2+}$ released from heme metabolism interacts with intracellular thiols and forms iron-sulfur. The nitrosylated form of the iron-sulfur cluster dinitrosyl iron-sulfur complex (DNIC) 


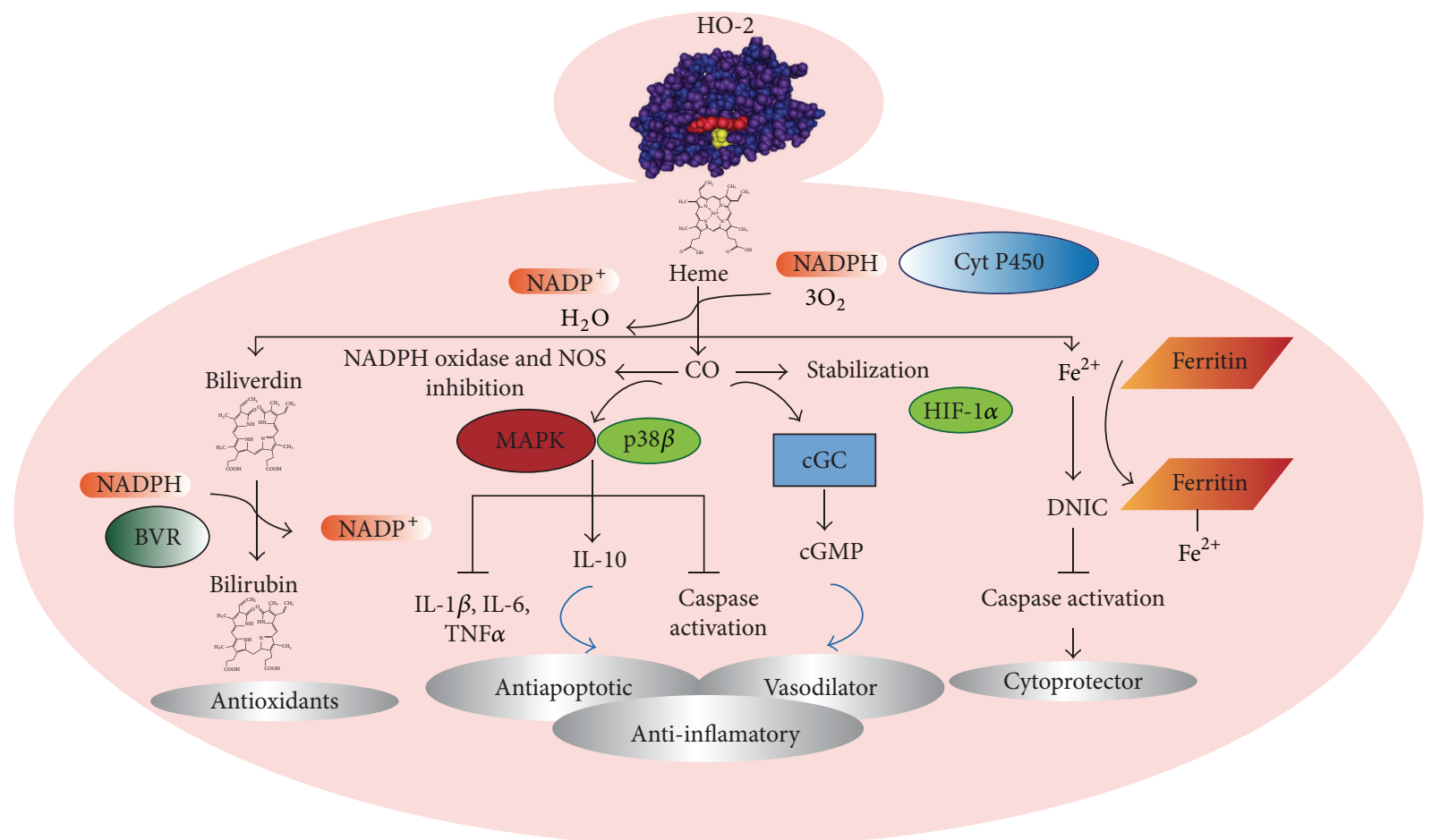

FIGURE 1: Physiological roles of HO-2 enzymatic activity products. Heme is cleaved by HO-2 producing equimolar amounts of $\mathrm{CO}$, Fe ${ }^{2+}$, and BV. Enzymatic reaction requires NADPH, Cyt P450, and $\mathrm{O}_{2}$. CO has antiapoptotic, antiproliferative, and anti-inflammatory activities through p38/MAPK processes. CO also regulates vascular tone via cGC/cGMP, stabilization of HIF- $1 \alpha$ and inhibits NADPH oxidase and NOS. BV is metabolized to $\mathrm{BR}$ by $\mathrm{NAD}(\mathrm{P}) \mathrm{H}: \mathrm{BVR}$. $\mathrm{Fe}^{2+}$ is sequestered by ferritin but also can form DNIC, a complex with protective effects through inhibition of caspases activity. BVR: biliverdin reductase; cGC: guanylate cyclase; DNIC: iron-sulfur cluster dinitrosyl iron-sulfur complex; HIF-1 $\alpha$ : alfa subunit of Hypoxia inducible factor-1; NO: nitric oxide; and NOS; nitric oxide synthase.

endogenously protects cells from NO-induced toxicity by either scavenging $\mathrm{NO}$ or converting $\mathrm{NO}$ to a potent Snitrosylating species. The participation of DNIC on different protective pathways has been suggested since the Snitrosylating species can inhibit activity of caspases through the S-nitrosylation of their active site Cys residue $[54,55]$ (Figure 1).

2.2. Elements of the HO System. The isoform 1 of the HO system was characterized as an enzyme entity in 1974 [56, 57]. Later, the characterization of two $\mathrm{HO}$ independent forms was reported [58]. The authors purified and characterized $\mathrm{HO}$ isoforms from liver microsomes and reported the differential response of both enzymes to different purification steps, thermolability, activity and response to cobalt, cadmium, hematin, phenylhydrazine, and bromobenzene. This was also the first time that the two isoenzymes were proposed as different entities and named as HO-1 and HO-2. The same group reported the complete purification and characterization of HO-2 isoform from rat testis [59]. A third isoform was described [60]; however it has been characterized in rats as a pseudogene derived from HO-2 transcripts [61].

To date, it is known that $\mathrm{HO}$ isoenzymes are microsomal proteins that catalyze the same reaction. They are the product of independent genes and there is no resemblance between the two isoforms at gene structure, regulation, or tissue expression patterns [8, 23]. In fact, it has been suggested that $\mathrm{HO}$ isoforms might have different cellular functions and physiological roles $[24,62]$.

HO-1 has a broad spectrum of inducers, including heme (its natural substrate), transition metals, $\mathrm{H}_{2} \mathrm{O}_{2}, \beta$-amyloid, dopamine, kainic acid, cytokines, prostaglandins, endotoxin, and vasoactive compounds as well as other pro-oxidants and inflammatory stimuli. It is also induced by heat shock, radiation, hypoxia and hyperoxia $[4,5,8]$. HO- 1 is abundantly expressed in spleen and other tissues that degrade senescent red blood cells, including specialized reticuloendothelial cells of the liver and bone marrow [6]. In fact, spleen is the only organ in which HO-1 is detected in unstressed conditions [8].

On the other hand, HO-2 has been considered as the constitutive isoform. High expression is observed in testis, brain, and endothelial and smooth cells from cerebral vessels $[9,10]$. HO-2 is the abundant isoform in rat adult brain. It has been detected in neuronal populations in forebrain, hippocampus, midbrain, basal ganglia, thalamic regions, cerebellum, and brain stem (reviewed in [8]). In contrast, $\mathrm{HO}-1$ is barely detected in brain tissue in the absence of stress inducers.

In the next section we recapitulate known information about the HO-2 isoform. HO-1 descriptions and comparisons when describing $\mathrm{HO}-2$ are inevitable. However, next sections do not pretend to be a work on the vast information on $\mathrm{HO}-1$, 


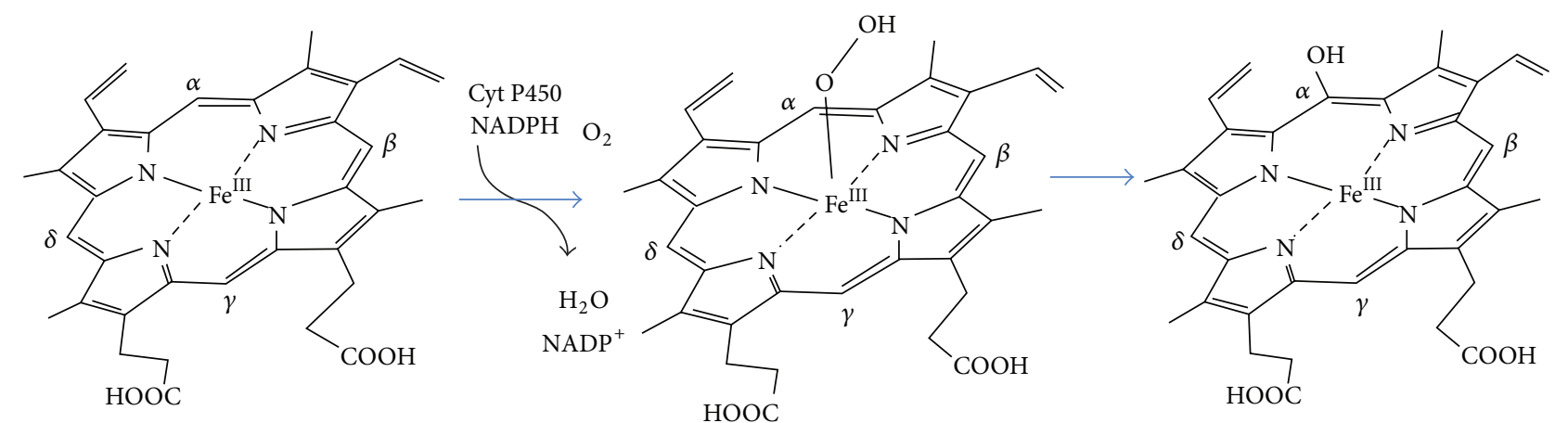

Heme

Ferric-hydroperoxide

$\alpha$-meso-hydroxyheme<smiles>CC1(CO)CC1C(=O)O</smiles>

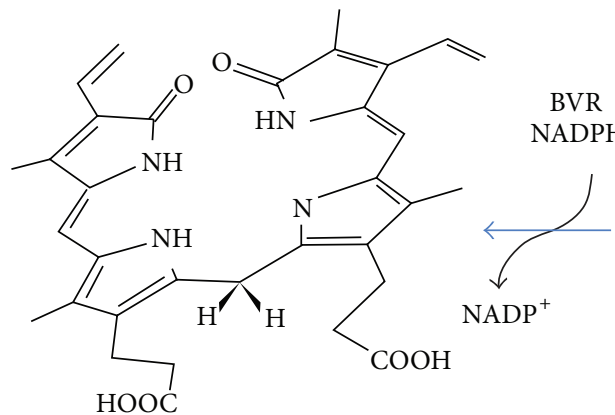

Bilirubin

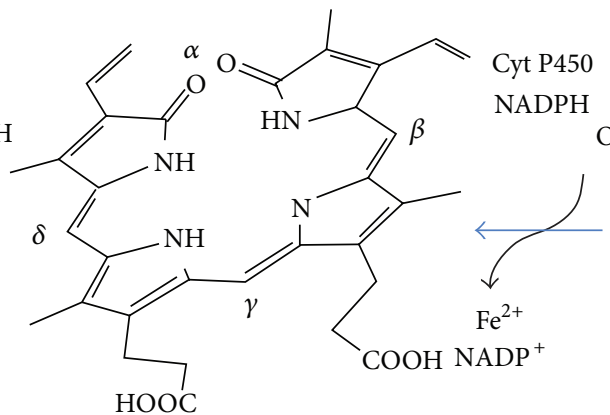

Biliverdin IX $\alpha$

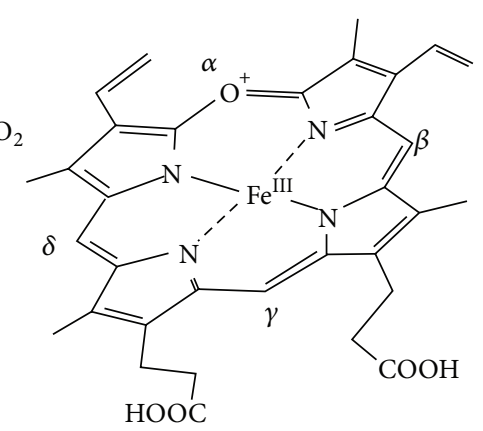

$\alpha$-verdoheme

FIgURE 2: Catalytic reaction of HOs and BVR. The sequence is shown in three stages, separated by three well-defined intermediates: ferrichydroperoxide, $\alpha$-meso-hydroxyheme, and $\alpha$-verdoheme. The final products of the reaction are CO, biliverdin IX $\alpha$, and Fe ${ }^{2+}$. Biliverdin IX $\alpha$ is then reduced by BVR.

but a specific description of the existing information of HO-2 gene, transcript, as well as protein structure and regulation of HO-2.

\section{Hemeoxygenase 2}

3.1. HO-2 Gene. HO-1 and HO-2 are single copy genes that differ in gene structure and organization. HO- 1 is encoded on chromosome 22 (22q12) in the human genome [71]. It is approximately $14 \mathrm{~kb}$ long, contains 5 exons, results from a single message of $1.8 \mathrm{~kb}$, and translates to a $32 \mathrm{kDa}$ protein [72]. HO-2 is encoded on chromosome 16 (16q12) [71] and has a complex organization. McCoubrek and Maines reported in 1994 the characterization and structure organization of the rat Hmox2. They showed that Hmox2 has a length of $12,563 \mathrm{pb}$, possesses 5 exon and 4 intron regions, and lacks a conventional TATA box.

Coding sequence of Hmoxl begins in exon 1, while the Hmox2 start codon is found in exon 2. Hmox 2 exon 1 is composed entirely of the noncoding sequence $5^{\prime}$ UTR [63] (Figure 3).
Particularly, Hmox 2 presents a nested sequence of 1046 nucleotides in the intron 1 with $87 \%$ identity to the cDNA encoding the mouse and human nonhistone chromosomal protein, HMG17 (Figure 3); a protein that facilitates the catenation of double-stranded DNA catalyzed by various topoisomerases and may confer specific conformations to transcribed regions in the genome [63].

3.2. HO-2 Transcripts and Regulation. In contrast to HO1 , which results from a single message [57], HO-2 is the product of two or more transcripts that translates a uniquely protein of $36 \mathrm{kDa}$. In most tissues, cell types, and mammalian species including human, two different sizes of 1.3 and 1.7$1.9 \mathrm{~kb}$ HO-2 transcripts have been identified. However, in rat, the presence of five HO-2 different transcripts with developmental and tissue-specific regulation has been demonstrated. The $1.45,1.7$ and $2.1 \mathrm{~kb}$ transcripts are unique to testis and expressed only in adulthood; the 1.45 transcript is the predominant form in testis, while 1.3 and $1.9 \mathrm{~kb}$ are common to every tissue examined $[63,64,73]$. In human, there are two HO-2 transcripts (1.3 and $1.7 \mathrm{~kb}$ ) [65], while mice show two 


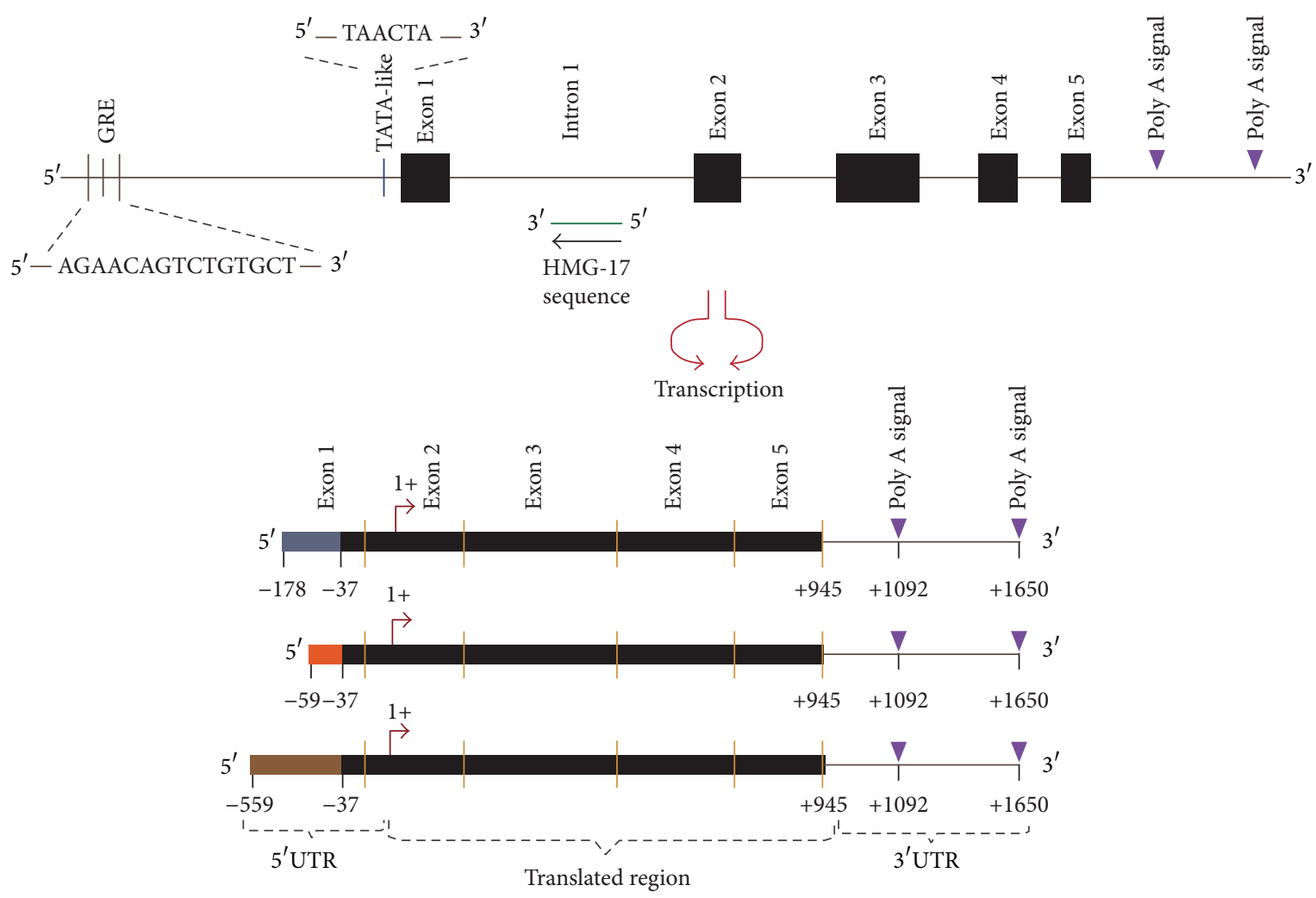

Figure 3: Structure of the Hmox2 and multiple transcripts of rat HO-2. Introns are denoted by thin lines, coding sequences by black boxes. In the promoter sequence, the TATA-like sequence is observed. The upstream regulatory sequence GRE is shown. Nested sequence HMG17 cDNA is indicated by a green line. Two potential polyadenylation signals are located in the $3^{\prime}$ UTR in a purple arrow. The start codon is denoted as +1 . Three different transcripts are identified as result of sequence variability in the upstream region from nucleotide -37 . Figure based on information reported by [63-65].

mRNAs named HO-2a and HO-2b [74]. Only one transcript of $1.7 \mathrm{~kb}$ has been identified in the monkey Cebus apella [75].

The different HO-2 transcripts result from processes such as differential initiation of transcription, alternative use of polyadenylation (poly A) sites or differential splicing, and stage-specific exon utilization. The identification of three different $5^{\prime}$ UTRs sequences in the untranslated first exon of the rat transcripts indicates alternative splicing in Hmox2 mRNA processing. This, plus the presence of two poly A signals separated by 560 nucleotides on Hmox2, allows generation of transcripts of different sizes [64] (Figure 3). The presence of secondary stem/loop structures between the two HO-2 poly A signals suggests that these loops provide binding sites for proteins that could be controlling RNA stability and translation.

Differential use of the poly A signals was determined in several tissues of rat. Relative abundance of the 1.3 and $1.9 \mathrm{~kb}$ transcripts varied in a tissue-specific manner, with approximately equal amounts of both messages in kidney and brain. In testis, the smaller transcript predominates, while the larger transcript is scarcely detected. In liver, only the smaller transcript was detected. Additionally, the translation analysis showed that the $1.3 \mathrm{~kb}$ transcript is more efficiently translated than the $1.9 \mathrm{~kb}$ transcript [73], suggesting posttranscriptional regulatory mechanisms through poly A signals $[64,65]$.
One of the most important differences between HO-1 and HO-2 arises from the presence of different regulatory elements in the promoter region. Control of HO-1 transcription is complex and tightly regulated, with differences in expression found between tissues and species. As mentioned before, a wide variety of stimuli induce HO-1 expression. Multiple regulatory elements control human $\mathrm{HO}-1$ gene transcription. These elements contain numerous transcription factor consensus binding sites in both the proximal and distal $5^{\prime}$ promoter sequences, as well as in an internal enhancer region. HO-1 gene expression can be upregulated through its multiple stress response as well as by numerous important transcription factors including Jun $B$, activator proteins 1 and 2 (AP-1 and 2), NF- $\kappa$ B, HIF-1, and Nrf2 $[6,76,77]$. Conversely, the transcription factors Bach1 and Jun $\mathrm{D}$ act as negative regulators of human $\mathrm{HO}-1$ gene expression $[78,79]$. In contrast to these various regulatory elements in Hmoxl promoter, the only demonstrated functional response element in Hmox2 promoter is the glucocorticoid response element (GRE) [80]. Enhanced transcription by GRE regulation has been demonstrated with corticosterone or dexamethasone treatment in brain of old or newborn rat, respectively, where an increase of HO-2 transcripts (1.3 and $1.9 \mathrm{~kb}$ ) and $\mathrm{HO}$ protein levels was observed $[80,81]$. A remarkable increase of the tissue specific 2.1-and-1.45 kb transcripts was observed in newborn 

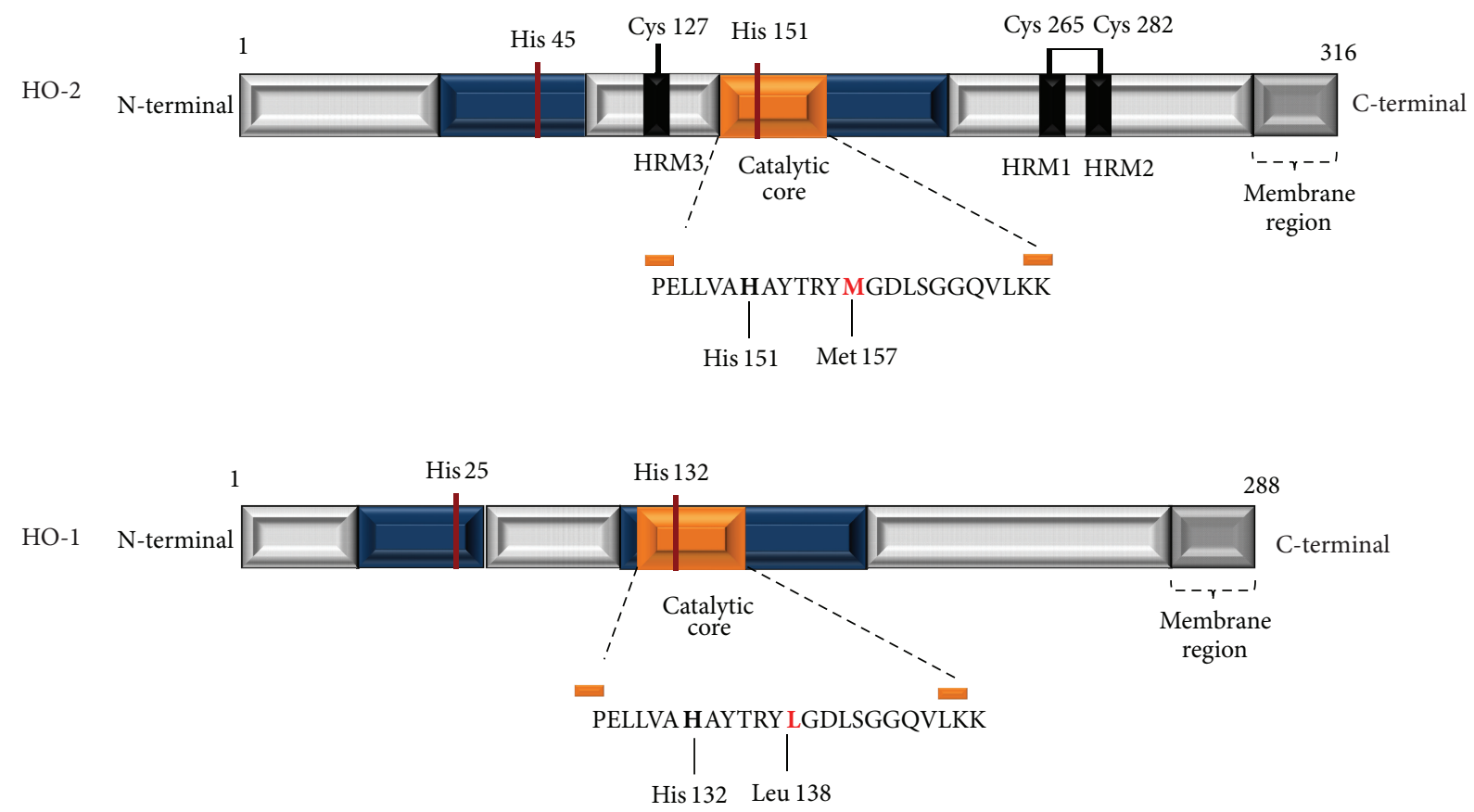

Conserved region

E Nonconserved region

FIGURE 4: Comparison between HO-1 and HO-2 primary structures. Figure based on information reported by [66-68].

rat testis [82] after corticosterone administration, suggesting the direct involvement of the adrenal glucocorticoids in Hmox 2 modulation.

3.3. HO-2 Protein Structure. HO-1 and HO-2 isoenzymes are homologous proteins that align in sequence and share the same fold and activity. The sequence identity of both proteins is $45 \%$ between full-length $\mathrm{HO}-1$ and $\mathrm{HO}-2$ and $55 \%$ in the conserved core regions. The core domains of both enzymes share a similar fold [66]. Crystal structure of the heme-free and-bound crystal structures of human HO-1 were described since 1999 [67]. More recently, Bianchetti et al. (2007) reported the apo- and heme-bound crystal structure of human HO-2 in a truncated form [66]. Additionally, the crystal structure of HO-2 from Synechocystis sp. PCC 6803 has been reported [83].

Crystallographic studies of HOs revealed that proteins are mostly $\alpha$-helical with short loop segments that connect adjoining helices. In general, the secondary structure of $\mathrm{HO}-$ 2 closely resembles apo- and heme-bound $\mathrm{HO}-1[67,83]$. Primary sequence alignment shows that HO-1 and $\mathrm{HO}-2$ exhibit two regions of sequence divergence: one is around residue 127 and the other is near the C-terminal between 240 and 295 (HO-2 numbering) (Figure 4) [66, 69]. Evidences show that differences in C-terminal of HO-1 and HO-2 play regulatory roles. It has been reported that $\mathrm{HO}-1$ undergoes a regulated intramembranal proteolysis of 52 amino acids at Cterminal in order to be translocated to the nucleus and it has been hypothesized that $\mathrm{HO}-1$ alters binding of transcription factors that respond to hypoxic or oxidative stress conditions affecting gene expression [84]. This proteolysis and nuclear translocation occurs in hypoxic conditions and is a specific behavior of HO-1 [85]. On the other hand, HO-2 in its C-terminal region contains particular sequences between residues 255 and 287 named the heme regulatory motifs (HRMs) (see below).

The catalytic core of HO-1 and HO-2 includes a 24 amino acid segment in the primary structure (that corresponds to residues 146 to 169 in human HO-2 and 126 to 149 in HO-1) perfectly conserved among all forms [8]. The only exception is the conservative substitution of a Leu residue found in all the known HO-1 proteins for a Met residue in $\mathrm{HO}-2$. This segment is hydrophobic and forms a heme pocket that binds the heme pyrrole rings 1 and 2 (with vinyl side chains) through electrostatic interactions. The conserved His 132 in HO-1 facilitates heme catalysis while in HO-2 (His 151) is essential for catalytic activity [86, 87] (Figure 4). The heme pocket is formed by two helices named proximal and distal. The proximal helix provides the residue that stabilizes heme into catalytic core (His 25 for HO-1 and His 45 for HO-2) coordinating heme iron through the $\tau$ nitrogen of imidazole $[66,88]$. Additionally, the carboxyl oxygen from Glu 49 forms a hydrogen bond with the $\pi$ nitrogen of imidazole from His 45 in order to stabilize the iron-coordinating His. Gly 163 moves away from the heme, causing the heme pocket to adopt the open conformation, which is proposed to be important in binding heme and/or releasing products [66]. 
Although the C-terminal HRM region shows the most significant sequence difference between $\mathrm{HO}-1$ and $\mathrm{HO}-2$, most of the key amino acids involved in heme binding, Lys 38, His 45, Glu 49, Tyr 154, Gly 159, Asp 160, Gly 163, Lys 199, and Arg 203 are observed in similar positions in the hemebound HO-2 structure when compared with heme-bound HO-1. The major differences in the crystal structure of apoHO-2 and heme-bound HO-1 are seen in the helices that directly interact with the heme. The proximal helix of apoHO-2 moves slightly downward and the distal helix moves upward relative to heme-bound $\mathrm{HO}-1$. In heme-bound $\mathrm{HO}-$ 2 , the same displacement of the distal helix is observed when compared with heme-bound HO-1 [66].

3.3.1. The Heme Regulatory Motifs in HO-2. A distinctive feature of HO-2 despite the high sequence identity and threedimensional homology in the core domains between HO-1 and HO-2 is the presence of the HRMs in HO-2 described in 1997 [89]. These motifs are known to control processes related to iron and oxidative metabolism in organisms ranging from bacteria to humans. A HRM consists of a conserved CysPro dipeptide core sequence that is usually flanked at the $\mathrm{N}$-terminal by basic amino acids and at the C-terminal by a hydrophobic residue. HRM/heme interactions have been proposed to regulate the activity and/or stability of proteins involved in respiration and oxidative damage, coordination of protein synthesis and heme availability in reticulocytes, and iron and heme homeostasis [90-92]. To date, only eight proteins that possess HRM domains have been identified. These proteins have a heme/oxygen regulatory function in the cell such as aminolevulinate synthase-1 and 2, Bach-1 transcriptional regulator of HO-1 expression, eukaryotic Initiation factor 2 (eIF2) Kinase, transcriptional activator Hap1, Iron regulatory protein 2 (IRP-2), iron responsive regulator (IRR), periodic-2 circadian regulator (Per2), and HO-2 [68, 89].

HO-2 contains two conserved HRMs involving Cys 265 in HRM1 and Cys 282 in HRM2. A third HRM (Cys 127) has also been reported for $\mathrm{HO}-2$, however its function is unknown [69]. The group of Maines described that these two HRMs bind heme with high affinity but are not involved in heme catalysis $[89,93]$. However, it was shown recently that the HRMs in HO-2 do not bind heme per se but form a reversible thiol/disulfide redox switch that indirectly regulates $\mathrm{HO}-2$ activity modulating substrate affinity. When the Cys of HRMs are in the reduced dithiol state, $K_{d}$ value for the HO-2-heme complex is around $350 \mathrm{nM}$. This value drops significantly to $33 \mathrm{nM}$, similar to the intracellular free heme level, when the HRMs switch to the oxidized disulfide state, indicating a much stronger affinity of oxidized $\mathrm{HO}-2$ for its substrate. Under oxidative stress conditions, HO-2 can degrade heme rapidly, increasing the levels of $\mathrm{CO}$ and $\mathrm{BV}$; however, hypoxic or reduced conditions increase cellular free heme $[68,89$, 94]. Recent results of Varfaj et al. have suggested that HRM heme affinity is not physiologically relevant [95]; however, the hypothesis of involvement of HRMs in redox switch and HO-2 participation in sensor oxygen system through $\mathrm{BK}_{\mathrm{Ca}}$ channel activity (see below) is supported by numerous evidences.
3.3.2. Modulation of HO-2 Activity. Abundant reports about the increase in HO-1 activity through enzyme induction exist. In contrast, there is a lack of information about HO-2 activation, with only a few reports appearing in the literature, which suggest that $\mathrm{HO}-2$ activity can be modified by different mechanisms.

It has been established that HO-2 activity is substrate dependent and that factors that increase heme substrate availability also increase $\mathrm{CO}$ production [96]. HO-2 activity can be affected by posttranslational modifications. In vitro studies have shown that HO-2 activity is influenced by CK2dependent phosphorylation at Ser 79 and that PKC protein could be implicated in this mechanism. In hippocampal culture, activation of PKC via phorbol ester treatment directly phosphorylates and activates CK-2, which in turn phosphorylates and activates HO-2 [97]. Authors suggested that HO-2 activation via PKC during neuronal depolarization could also involve $\mathrm{Ca}^{2+}$ entry. Later they demonstrated that $\mathrm{Ca}^{2+}$ mobilizing agents, such as ionomycin and glutamate, stimulate endogenous $\mathrm{HO}-2$ activity in primary cortical culture. Results using a calmodulin mutant Phe 66 (a key amino acid in the calmodulin binding motif) showed that this $\mathrm{Ca}^{2+} /$ calmodulin activation depends on the interaction between calmodulin and HO-2 and that this phenomenon is independent of CK2 activation. Apparently conformational changes in HO-2 induced by calmodulin binding are responsible for HO-2 activation. A similar conformational change in HO-2 could be occurring by phosphorylation of Ser 79 even both HO-2 activation mechanisms are independent and not additive [98]. The HO-2 activation by $\mathrm{Ca}^{2+} /$ calmodulindependent mechanisms by glutamate has been also observed in piglet astrocytes [99]. Although actually it is not completely clear, it has been suggested that tyrosine phosphorylation stimulates HO-2 catalytic activity. Results showed that a PTK inhibitor reduces the HO-2 catalytic activity in cerebral microvessels, while the inhibition of protein tyrosine phosphatases increases it [100] (Figure 5(a)).

HO-2 activity can also be regulated by the presence of $\mathrm{NO}$ and ROS. Experiments with recombinant wt HO-2 and Cys 264/Cys $281 \rightarrow$ Ala/Ala mutant showed the inhibition of wt protein but not the mutant, suggesting NO binding to HRMs as responsible of HO-2 activity inhibition [101]. Later, it was described that glutamate increases NOS activity with the concomitant increase in $\mathrm{NO}$, which in turn stimulates HO-2 activity. The hypothesis proposed is that this stimulation occurs through an increase in cGMP levels [102]. The same group has proposed that ROS work as regulators of HO-2 activity. In isolated cerebral vessels and cerebral vascular endothelial cells challenged with TNF- $\alpha$, NADPH oxidase 4 (Nox4)-derived ROS increase HO-2 activity and $\mathrm{CO}$ production promoting survival of brain endothelial cells. These evidences support the hypothesis that $\mathrm{HO}-2$ is a redox-sensitive enzyme posttranslationally activated by ROS through the thiol/disulfide redox molecular switch [103].

A specific potent activator of HO-2 is menadione (Vitamin K3). It increases HO-2 enzymatic activity up to 30 -fold in an in vitro model. An increase in $V_{\max }$ without changes in the apparent $K_{m}$ was observed. Up to date, it is the only report 


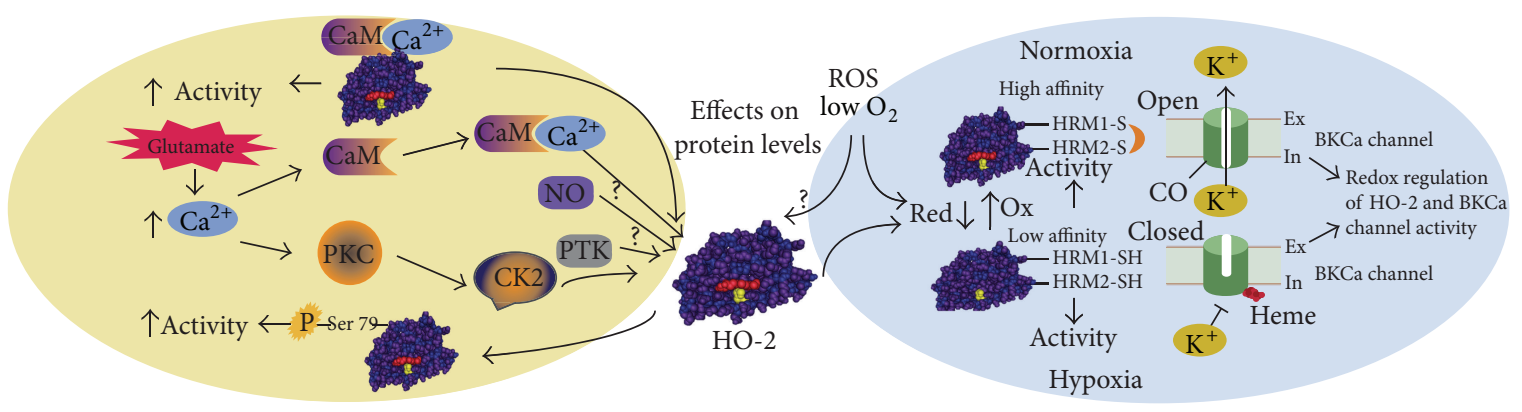

(a)

(b)

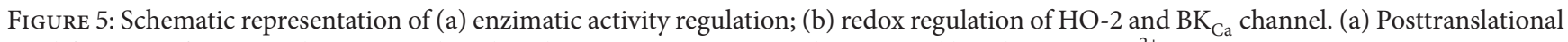
modifications of HO-2 such as Ser 79 phosphorylation via PKC/CK2 can be activated by Glutamate/Ca ${ }^{2+}$, increasing $\mathrm{HO}-2$ enzimatic activity. $\mathrm{CaM} / \mathrm{Ca}^{2+}$ complex also can increase HO-2 activity through interaction between CaM and HO-2 due to an increase of $\mathrm{Ca}^{2+}$ by $\mathrm{Glutamate}$ PTK may increase the activity of HO-2. (b) HO-2 and $\mathrm{BK}_{\mathrm{Ca}}$ constitute a universal oxygen sensor system. Normoxic conditions: $\mathrm{BK}_{\mathrm{Ca}}$ channel opens because inhibitor heme has dissociated from the channel or because CO generated by HO-2 is bound. In hypoxic conditions, CO levels are low and heme is bound to channel, hence $\mathrm{BK}_{\mathrm{Ca}}$ is closed. Thus, heme is bound to HO-2 under normoxic conditions and to the HBD of the $\mathrm{BK}_{\mathrm{Ca}}$ channel under hypoxia. Based on hypothesis proposed by Yi and Ragsdale 2007 [69] Williams et al. 2004 [70]; see text for details. $\mathrm{BK}_{\mathrm{Ca}}$ channel: voltage- and $\mathrm{Ca}^{2+}$-activated large conductance $\mathrm{K}^{+}$channel; CaM: calmodulin; CK2: Casein Kinase 2; PKC: Protein Kinase C; and PTK: Protein Tyrosine Kinase.

that had identified a molecule that affects HO-2 activity specifically. Since menadione has no effect on the activity of HO-1 it has been suggested that it or its pharmacological offspring should be useful in the elucidation of physiological and pathological roles of HO-2 in the central nervous system (CNS) and other organs [104].

Regulation of catalytic activity of $\mathrm{HO}$ system is critical for survival processes in the cell. Two peculiar facts show that $\mathrm{HO}$ activity has many interesting unresolved issues. First, results with the inactive mutant $\mathrm{HO}-2-\mathrm{H} 45 \mathrm{~A}$ and second, the $\mathrm{HO} 1: \mathrm{HO} 2$ complex formation, with implications in $\mathrm{HO}$ activity. In the first case, Kim \& Doré (2005) demonstrated that the addition of hemin to cells overexpressing wt or $\mathrm{H} 45 \mathrm{~A}$ mutant provokes increased cellular damage in H45Acells due to its impossibility to metabolize heme. However, the use of $\mathrm{H}_{2} \mathrm{O}_{2}$ showed that $\mathrm{HO}-2 \mathrm{H} 45 \mathrm{~A}$ was also able to protect cells against oxidative stress injury, suggesting the multiplicity of action of the HO-2, besides its essential catalytic activity [105]. The other concern involves a physical interaction between HO-1 and HO-2. Using cell free systems and tissues, it was demonstrated that first 44 residues in $\mathrm{HO}-$ 2 binds to $58-80$ residues in HO-1 forming a HO-1: HO2 complex. This complex arrangement results in decreased activity of the $\mathrm{HO}$ system. Apparently, this interaction serves to limit $\mathrm{HO}$ activity in certain tissues such as brain. The regulation of $\mathrm{HO}$ enzyme activity by $\mathrm{HO}-1$ binding to $\mathrm{HO}-$ 2 could represent a useful negative feedback mechanism to limit $\mathrm{HO}$ activity when there is an excess of HO protein [106].

The main difficulty on $\mathrm{HO}$ activity regulation research and the specific contribution of HO-1 or HO-2, is the absence of specific inhibitors. In fact, the activity reported in many in vivo works is the result of total $\mathrm{HO}$ system. In the majority of cases, HO-1 or HO-2 activity is attributed to the abundance of each isoform in a particular tissue, or to the induction of HO-1 enzyme. Traditionally, competitive HO inhibitors such as the metalloporphyrins have been used owing to their structural similarity with heme [107]. However, the use of these inhibitors has been criticized since they are not selective between $\mathrm{HO}$ isoforms, leading some investigators to doubt the validity of the interpretation of the results obtained using these molecules. Despite the homology and high similarity between HO-1 and HO-2, proximal and distal helices in the apo- and heme-bound crystallographic data show that these particular differences open the possibility to design specific inhibitors. Recent reports have shown that imidazoledioxolane compounds and other nonporphyrin molecules are selective inhibitors of HO isoenzymes; however a more specific inhibition has been observed for HO-1 isoform, promising powerful pharmacological tools to elucidate the regulatory characteristics of the HO system [108-110].

\section{The Protective Role of $\mathrm{HO}-2$}

Cerebral tissue has a differential distribution of both isoenzymes. Although HO-1 is expressed barely in brain it has been detected in specific regions such as dentate gyrus, hipothalamus ventromedial, and any nucleus of brain stem. In contrast, HO-2 is expressed in abundant form in brain, where it is localized in neuronal populations in forebrain, hippocampus, midbrain, basal ganglia, thalamic regions, cerebellum, and brain stem. At cellular level, both isoenzymes have a different expression pattern due to the fact that HO-2 is expressed basically in neuronal populations, while HO-1 expression is markedly increased in glial cells and astrocytes by oxidative stress $[111,112]$. It suggests that the two isozymes have individual roles, particularly in brain. HO-1 induction has been shown to selectively protect cultured cortical astrocytes, but not neurons, from oxidative stress resulting from exposure to hemoglobin and hydrogen peroxide [113, 114]. HO-2, on the other hand, is constitutively expressed in neurons throughout the brain and its expression has been shown to protect against apoptotic cell death in cortical, hippocampal, and cerebellar 
granule cultures and in vivo models of ischemic injury [1618]. Besides, it has been suggested that $\mathrm{HO}-2$ is responsible for the production of $\mathrm{CO}$ for physiological functions in neuronal populations and that is the first isoenzyme that responses to cellular damage in cerebral tissue due to its high expression in this organ.

A growing number of reports suggest the significant role of HO-2 in several in vivo and in vitro models [115]. First observations were reported by the group of Sylvain Doré who observed that neuronal damage or brain volume swell are increased in HO-2 (-/-) mice subjected to ischemia (in contrast to HO-1 (-/-) mice that did not show neuronal damage) [17] or in a model of intracerebral hemorrhage [116]. Intracranial injections of NMDA also showed increased neuronal damage in HO-2 (-/-) mice [17].

A traumatic brain injury model using HO-2 (-/-) animals shows HO-1 induction as a result of the imposed damage. However, a reduction in the total activity of $\mathrm{HO}$ system accompanied by cell loss in cortex, CA3 hippocampus region and lateral dorsal thalamus was observed, suggesting that HO-2 activity is crucial to protect neurons through heme catabolism [117]. In vivo or in vitro deletion of HO2 exacerbates inflammation induced damage $[118,119]$ and inflammatory molecules such as IL-1, IL- 6 and NF- $\kappa$ B are increased in aortic endothelial cells obtained from $\mathrm{HO}-2$ null mice [120].

Basal levels of HO-2 participate not only in maintaining heme homeostasis but also in the cellular defense mechanisms against oxidative stress by regulating extracellular superoxide dismutase (EC-SOD), Akt, and apoptotic signaling kinase-1 (ASK-1), presumably by influencing the rate of heme degradation to $\mathrm{BR}, \mathrm{CO}$, and $\mathrm{Fe}^{2+}$. After silencing $\mathrm{HO}-2$, a decrease in EC-SOD and phosphorylated Akt (Ser 473 and Thr 308) was observed affecting Bad and Bax regulation and increasing the proapoptotic protein ASK-1 in renal tissue of mice, suggesting that the control of EC-SOD, Akt, 3-NT, and ASK-1 by HO-2 is critical in the regulation of apoptosis [121].

Recently, it has been described that NO-induced apoptosis depends on the capability of cells to express $\mathrm{HO}$ system and $\mathrm{p} 53$. In vascular smooth muscle cells, NO significantly elevated HO-2 protein levels in wild-type p53 cells but not in knock-out p53 cells, without altering HO-2 mRNA levels in both cell types. Probably this change of HO-2 protein expression is due to translational or posttranslational regulation of HO-2 expression in a p53-dependent manner. Catalytic activity of $\mathrm{HO}$ is critically involved in the protective effect of p53 on NO-induced cell death, indicating that HOmediated heme metabolites are important for cell protection [55] (Figure 1).

Other evidences that support a protective role of HO2 in different models are the coordinated expression of BVR and HO-2 which promotes cardiomyocyte survival in response to isoproterenol [122]; the HO-2 involvement in the signal transduction pathway responsible to morphine tolerance through CO production [123]; and the coordinated expression and protein interaction of 6-phosphofructo-2kinase/fructose-2,6-bisphosphatase 4 (PFKFB4) and HO-2 in glucose homeostasis in HepG2 human hepatome cells [124].

\section{HO-2 and Hypoxia}

5.1. HO-2 and Its Role in Oxygen Response. A unique function described for HO-2 is its role in oxygen sensing and hypoxic response in mammalian cells. In 1997, Maines proposed for the first time a heme/oxygen sensor function for HO-2 [8]. This proposal was based in the identification of the HRMs in HO-2 protein sequence [89] (see Section 3.3.1) and of the oxygen-sensing consensus sequence $5^{\prime}$ TTTTGCA $3^{\prime}$ in the $3^{\prime}$ UTR of HO-2 mRNA. This sequence is located between the two poly A signals of the transcripts of $\mathrm{HO}-2$ and is $100 \%$ identical to the oxygen-sensing consensus sequence of the erythrophoietin gen, which responds to variations in oxygen concentration [125]. This $3^{\prime}$ flanking region of the Hmox 2 contains many inverted repeats which enable the formation of stem-loops, that may participate in transcriptional regulation expression and at RNA level could bind proteins that stabilize or destabilize the mRNA. Shibahara et al. (2007) support the proposal of $\mathrm{HO}-2$ as an $\mathrm{O}_{2}$ sensor based on morphometric changes observed for HO-2 -/- mice (reviewed in [24]).

Additionally, Williams et al. (2004) [70] and Yi and Ragsdale (2007) [69] have suggested that this oxygen sensor activity of HO-2 is related to the regulation of the activity of the carotid body $\mathrm{BK}_{\mathrm{Ca}}$ channel, and that those actions are linked to redox signals as well as to heme and CO metabolism.

Carotid bodies are arterial chemoreceptors that sense changes in blood gases and respond to hypoxia events secreting acetylcholine, dopamine, and ATP [126-130]. These signals promote and increase rate and depth of ventilation as a response to systemic hypoxia [131]. The hypoxia response element within the carotid body is the glomus cell. $\mathrm{K}^{+}$ channels on the plasmatic membrane of the glomus cells are inhibited during hypoxia, promoting cell depolarisation, $\mathrm{Ca}^{2+}$ influx, and transmitter release. In rat glomus cells, two $\mathrm{K}^{+}$channels have been implicated in the hypoxiadependent depolarization, the tandem $\mathrm{P}$-domain $\mathrm{K}^{+}$channels family (TASK sub-type) [132], and the $\mathrm{Ca}^{2+}$-activated large conductance $\mathrm{K}^{+}$channels $\mathrm{BK}_{\mathrm{Ca}}[133]$.

$\mathrm{BK}_{\mathrm{Ca}}$ channels are conductance $\mathrm{Ca}^{2+}$-activated $\mathrm{K}^{+}$channels involved in neural firing, muscle contraction, hearing, and vascular tone modulation activated by membrane depolarization and the increase in intracellular $\mathrm{Ca}^{2+}$. Activation of $\mathrm{BK}_{\mathrm{Ca}}$ channels repolarizes the cell membrane and leads to closing of voltage gated $\mathrm{Ca}^{2+}$ channels, working as a key negative feedback regulator of both membrane potential and intracellular $\mathrm{Ca}^{2+}$ levels (reviewed in [134]). $\mathrm{BK}_{\mathrm{Ca}}$ channels are composed of four $\alpha$ subunits forming a pore, each subunit with two domains at the C-terminal named RCK1 and RCK2 that work as regulators of conductance for $\mathrm{K}^{+}$. RCK1 also serves as $\mathrm{H}^{+}$sensor and appears to be involved in inhibition of the $\mathrm{BK}_{\mathrm{Ca}}$ channel by heme and activation by $\mathrm{CO}[135,136]$. It has been proposed that heme, $\mathrm{CO}$, and $\mathrm{HO}-2$ bind to a linker region between the two RCK domains, named the heme binding domain (HBD) [137].

Based on observations that demonstrated that $\mathrm{CO}$ is capable of activating $\mathrm{BK}_{\mathrm{Ca}}$ in carotid body [138], and the presence of HO-2 in the carotid body [139], Williams et al. (2004) demonstrated that $\mathrm{HO}-2$ and $\mathrm{BK}_{\mathrm{Ca}}$ channels have a physical interaction. Using electrophysiological assays with 
HEK293 cells, the authors demonstrated that CO modifies $\mathrm{BK}_{\mathrm{Ca}}$ channels activity, supporting the notion that HO-2 activity is crucially involved in $\mathrm{BK}_{\mathrm{Ca}}$ channel activity and regulation. The group of Kemp proposed a model in which $\mathrm{O}_{2}$ sensing is conferred upon the $\mathrm{BK}_{\mathrm{Ca}}$ channel by colocalization with $\mathrm{HO}-2$ [70]. In normoxia, HO-2 activity generates $\mathrm{CO}$ which is a channel activator and ensures that the $\mathrm{BK}_{\mathrm{Ca}}$ channel is open at normal systemic $\mathrm{O}_{2}$ levels. Cellular $\mathrm{CO}$ levels are reduced during a hypoxic challenge as $\mathrm{HO}-2$ substrate $\left(\mathrm{O}_{2}\right)$ becomes scarce and $\mathrm{CO}$ production is dramatically reduced. This reduction in $\mathrm{CO}$, in possible combination with direct heme-dependent inhibition evokes channel closure $[70,140]$.

More recently, it has been proposed that HRMs in HO-2 serve as a thiol/disulphide redox switch regulating binding of heme and that this switch in $\mathrm{HO}-2$ responds to cellular oxidative stress and reductive conditions. Ragsdale group proposes that HRMs act as a "molecular rheostat" that responds to intracellular redox potential, controlling HO-2 activity by regulating heme binding in functions of hypoxic response in the carotid body $[69,94]$. Results indicate that $\mathrm{BK}_{\mathrm{Ca}}$ channels are regulated by a thiol/disulfide mediated redox switch as follows: (1) In normoxic conditions, $\mathrm{O}_{2}$ switches the thiol/disulfide of $\mathrm{HO}-2$ and that of the $\mathrm{BK}_{\mathrm{Ca}}$ channel to the disulfide state. In this state, $\mathrm{HO}-2$ has high affinity for heme, in contrast to the low heme affinity of $\mathrm{BK}_{\mathrm{Ca}}$ channel. It results in the opening of the channel, since heme is dissociated from the HBD or the $\mathrm{CO}$ generated by HO-2 is bound. (2) In hypoxic conditions, $\mathrm{HO}-2$ loses affinity for heme, resulting in low heme degradation and $\mathrm{CO}$ production rates. The increase in local heme levels and decrease in $\mathrm{CO}$ concentrations allow the closing of $\mathrm{BK}_{\mathrm{Ca}}$ channel (Figure 5(b)). In other words, authors propose that HO-2 functions as a sensor of acute reduction in environmental $\mathrm{O}_{2}$ by regulating $\mathrm{BK}_{\mathrm{Ca}}$ channel activity changing the balance between intracellular heme concentrations, the production of $\mathrm{CO}$, and cellular redox state $[68,69,94]$.

5.2. HO-2 Response in Hypoxic Events. HO-2 deficient mice show hypoxemia, a blunted hypoxic ventilator response, hypertrophy of the pulmonary venous myocardium and enlargement of the carotid body, supporting the proposal that HO-2 participates in the oxygen response [24]. In the last years, several evidences suggest that HO-2 participates in the hypoxic response of certain tissues and cell types and that its expression is differentially regulated by oxygen tension.

HO-2 expression has shown to respond to hypoxia. For example, normobaric hypoxia decreased HO-2 protein by $40 \%$ in mouse liver after 7 days [141] and reduced levels in placenta of women that live in high altitude and chronic hypoxia have been reported [142]. Reduction of HO-2 as a consequence of hypoxic conditions has also been observed in vitro. Results obtained using different human cell lines show that HO-2 mRNA and protein are reduced [19]. They also demonstrated the half-life time of HO-2 transcript is reduced from 12 to $6 \mathrm{~h}$ without any effect on HO-1 mRNA. Since heme content was increased in some cell lines after $48 \mathrm{~h}$ hypoxia, they proposed that the observed reduction in HO-2 is an important adaptation of some human cell lines to maintain intracellular heme levels in oxygen reduction conditions. In addition, determination of HO-1 and HO-2 expression in mice subjected to normobaric hypoxia showed that there were no significant changes in the overall expression of HO-1 and HO-2 mRNAs and proteins in the lung during hypoxia. Nevertheless, immunohistochemical analysis showed that both isoforms were increased after 28 days of normobaric hypoxia in the pulmonary venous myocardium [141], suggesting a tissue specific differential regulation of $\mathrm{HO}$ system.

An interesting regulation of $\mathrm{HO}-2$ expression has been described using human umbilical vein endothelial cells and human aortic endothelial cells subjected to hypoxia. He et al. (2010) observed that, under hypoxic conditions, HO-2 protein levels were maintained even $57 \%$ reduction in steadystate HO-2 mRNA level and 43\% reduction in total protein synthesis were observed. Polysome profiling results revealed an increase of association of HO-2 transcript with polysomes during hypoxia. This association correlates with enhanced translation of HO-2 transcripts as a mechanism by which HO-2 protein levels are preserved. In fact, they observed that HO-2 maintains endothelial viability during hypoxic episodes, since inhibition of HO-2 expression provokes mitochondrial membrane depolarization, caspases activation, and apoptotic cell death [20].

In aortic endothelium of rats submitted to hypoxia, HO2 protein increases, suggesting that endothelial modulation of rat aortic contraction to phenylephrine is mediated by HO-2. Apparently, this modulation is due to inhibition of ET-1 potentiation of $\alpha$-adrenoceptor-induced contraction, suggesting the existence of an unrecognized mechanism by which $\mathrm{HO}$ inhibits systemic vascular reactivity in diseases that involve the absence or decrease of oxygen concentrations [143].

A significant increase in HO-2 protein expression was observed in hypoxia-induced animals, apparently due to the presence of a hypoxic global damage, which can upregulate vascular endothelial growth factor and promote the subsequent proliferation of endothelial cells. This result indicates that the observed HO-2 upregulation and the increase in $\mathrm{HO}$ 1 immunoreactivity is involved in the reduction of cell death induced by the absence of oxygen [144].

Finally, using electrophysiologic recordings a relationship between membrane excitability and HO-2 expression and activity in hypoxic conditions was observed. HO2 is expressed in the hypoxia-chemosensitive regions of the rostral ventrolateral medulla (RVLM). Cardiorespiratory regions of the RVLM are excited by local hypoxia and RVLM neurons have shown to respond to $\mathrm{NaCN}$ and low $\mathrm{O}_{2}$ with either depolarization or hyperpolarization. The addition of HO inhibitor SnPP-IX blocks the depolarization response of hypoxia-excited neurons to both $\mathrm{NaCN}$ and low $\mathrm{O}_{2}$, but has no effect on the hyperpolarization response of hypoxiadepressed neurons. HO-2 is observed only in the hypoxiaexcited neurons. These results suggest that RVLM neurons are excited by hypoxia via a HO-2-dependent mechanism. Apparently, hypoxic-induced increase in intracellular $\mathrm{Ca}^{2+}$ 
could enhance HO-2 activity by activating protein kinases (PKC/CK2). The products of $\mathrm{HO}$ reaction could modulate the conductance of ion channels and change neuronal excitability [145].

\section{Concluding Remarks}

In this review, we have addressed the issue of the HO system as a potent endogenous antioxidant cell defense system. The fact that HO-1 actively responds to stress conditions has meant this isoform as a protein of great interest to many groups. In contrast, since its discovery and characterization $[58,59]$, HO-2 has shown unique features. Despite the two isoforms homology, their almost identical primary and tertiary structures and the fact that both perform the same catalytic reaction, these isoforms present relevant differences at regulation of transcription, translation, and catalytic activity processes, as well as in their expression pattern at different cell types and tissues. These differences prompt intense investigation on their regulatory capacities at comparative levels.

Herein, we have also provided reviewed evidence that HO-2 participates in a multitude of housekeeping functions, mainly in brain, since it is the most prominent expressed isoform and the first to respond against oxidative stress. Indeed, the relevance of HO-2 for the CNS is emphasized by evidence showing that the continuous and regulated endogenous $\mathrm{CO}$ production by the activity of this enzyme is a key factor for maintaining the physiological function in neuronal cells and the vascular tone regulations of the cerebral blood vessels. Further support to this concept came from experiments with HO-2 deficient animals, demonstrating its involvement in brain cell damage produced by cerebral ischemia and intracerebral hemorrhage [16, 17]. For sure, enlightening studies will provide stronger evidence of this topic in a near future. In the meantime, some limitations should be considered in this process: as we have mentioned in the HO2 activity section, the absence of specific pharmacological inhibitors for each isoform has complicated the inference of the independent contribution of each isoform to the studied models. However, important advances have been obtained from imidazole-dioxolane derivatives [110-112]. Therefore, more attention shall be paid to the production of new and more specific inhibitors of both $\mathrm{HO}$ isoforms if we want to bring an accurate pharmacological approach to the role of these enzymes in the physiology of the CNS. As a temporary shortcut, in recent years, the use of siRNAs has shown to importantly contribute to clarify the role of each isoform in different models.

With respect to the described novel function of HO-2 as $\mathrm{O}_{2}$ sensor, this issue opens a refreshing line of research to be explored in the next years. In this regard, future research shall clarify in a more precise manner all those functions that HO-2 already exerts. Moreover, it is pertinent to point out that even when HO-2 does not respond to the numerous stimuli compared with HO-1-mainly due to the absence of regulatory elements in its promoter-its expression at mRNA and protein levels is influenced by hypoxia conditions. This evidence might suggest that the role of $\mathrm{HO}-2$ as a constitutive enzyme is questionable, especially during the occurrence of events related with varying oxygen levels, and this is particularly relevant for our knowledge of the pathological processes affecting the CNS, particularly those related with hypoxia, ischemia, hypertension, and instabilities of respiration. Thus, the role of HO-2 as a sensor of oxygen concentrations will shape future research on this field.

\section{Conflict of Interests}

The authors declare that there is no conflict of interests regarding the publication of this paper.

\section{Acknowledgments}

Jorge Muñoz-Sánchez acknowledges the scholarship and financial support provided by the National Council of Science and Technology (CONACyT) and the National Autonomous University of Mexico (UNAM).

\section{References}

[1] T. Yoshida and C. T. Migita, "Mechanism of heme degradation by heme oxygenase," Journal of Inorganic Biochemistry, vol. 82, no. 1-4, pp. 33-41, 2000.

[2] G. Kikuchi, T. Yoshida, and M. Noguchi, "Heme oxygenase and heme degradation," Biochemical and Biophysical Research Communications, vol. 338, no. 1, pp. 558-567, 2005.

[3] S. Kumar and U. Bandyopadhyay, "Free heme toxicity and its detoxification systems in human," Toxicology Letters, vol. 157, no. 3, pp. 175-188, 2005.

[4] P. A. Dennery, "Regulation and role of heme oxygenase in oxidative injury," Current Topics in Cellular Regulation, vol. 36, pp. 181-199, 2001.

[5] H. M. Schipper, "Heme oxygenase-1: role in brain aging and neurodegeneration," Experimental Gerontology, vol. 35, no. 6-7, pp. 821-830, 2000.

[6] S. W. Ryter, J. Alam, and A. M. K. Choi, "Heme oxygenase1/carbon monoxide: from basic science to therapeutic applications," Physiological Reviews, vol. 86, no. 2, pp. 583-650, 2006.

[7] M. D. Maines, "Heme oxygenase: function, multiplicity, regulatory mechanisms, and clinical applications," The FASEB Journal, vol. 2 , no. 10, pp. 2557-2568, 1988.

[8] M. D. Maines, "The hemeoxygenase system: a regulator of second messenger gases," Annual Review of Pharmacology and Toxicology, vol. 37, pp. 517-554, 1997.

[9] R. Zakhary, S. P. Gaine, J. L. Dinerman, M. Ruat, N. A. Flavahan, and S. H. Snyder, "Heme oxygenase 2: endothelial and neuronal localization and role in endothelium-dependent relaxation," Proceedings of the National Academy of Sciences of the United States of America, vol. 93, no. 2, pp. 795-798, 1996.

[10] H. Zhao, R. J. Wong, X. Nguyen et al., "Expression and regulation of heme oxygenase isozymes in the developing mouse cortex," Pediatric Research, vol. 60, no. 5, pp. 518-523, 2006.

[11] R. Gozzelino, V. Jeney, and M. P. Soares, "Mechanisms of cell protection by heme Oxygenase-1," Annual Review of Pharmacology and Toxicology, vol. 50, pp. 323-354, 2010.

[12] E. Aztatzi-Santillán, F. E. Nares-López, B. Márquez-Valadez, P. Aguilera, and M. E. Chánez-Cárdenas, "The protective role of 
heme oxygenase-1 in cerebral ischemia," Central Nervous System Agents in Medicinal Chemistry, vol. 10, no. 4, pp. 310-316, 2010.

[13] R. Stocker and M. A. Perrella, "Heme oxygenase-1: a novel drug target for atherosclerotic diseases?" Circulation, vol. 114, no. 20, pp. 2178-2189, 2006.

[14] W. Durante, "Heme oxygenase-1 in growth control and its clinical application to vascular disease," Journal of Cellular Physiology, vol. 195, no. 3, pp. 373-382, 2003.

[15] M. L. Wu, Y. C. Ho, C. Y. Lin, and S. F. Yet, "Heme oxygenase-1 in inflammation and cardiovascular disease," American Journal of Cardiovascular Disease, vol. 1, no. 2, pp. 150-158, 2011.

[16] S. Doré, M. Takahashi, C. D. Ferris, L. D. Hester, D. Guastella, and S. H. Snyder, "Bilirubin, formed by activation of heme oxygenase-2, protects neurons against oxidative stress injury," Proceedings of the National Academy of Sciences of the United States of America, vol. 96, no. 5, pp. 2445-2450, 1999.

[17] S. Doré, K. Sampei, S. Goto et al., "Heme oxygenase-2 is neuroprotective in cerebral ischemia," Molecular Medicine, vol. 5, no. 10, pp. 656-663, 1999.

[18] S. Doré, S. Goto, K. Sampei et al., "Heme oxygenase-2 acts to prevent neuronal death in brain cultures and following transient cerebral ischemia," Neuroscience, vol. 99, no. 4, pp. 587-592, 2000.

[19] Y. Zhang, K. Furuyama, K. Kaneko et al., "Hypoxia reduces the expression of heme oxygenase-2 in various types of human cell lines: a possible strategy for the maintenance of intracellular heme level," FEBS Journal, vol. 273, no. 14, pp. 3136-3147, 2006.

[20] J. Z. He, J. J. D. Ho, S. Gingerich, D. W. Courtman, P. A. Marsden, and M. E. Ward, "Enhanced translation of heme oxygenase-2 preserves human endothelial cell viability during hypoxia," The Journal of Biological Chemistry, vol. 285, no. 13, pp. 9452-9461, 2010.

[21] F. Han, K. Takeda, S. Yokoyama et al., "Dynamic changes in expression of heme oxygenases in mouse heart and liver during hypoxia," Biochemical and Biophysical Research Communications, vol. 338, no. 1, pp. 653-659, 2005.

[22] M. D. Maines, "The heme oxygenase system: update 2005," Antioxidants and Redox Signaling, vol. 7, no. 11-12, pp. 1761-1766, 2005.

[23] M. D. Maines and P. E. M. Gibbs, "30 Some years of heme oxygenase: From a "molecular wrecking ball" to a "mesmerizing" trigger of cellular events," Biochemical and Biophysical Research Communications, vol. 338, no. 1, pp. 568-577, 2005.

[24] S. Shibahara, F. Han, B. Li, and K. Takeda, "Hypoxia and heme oxygenases: oxygen sensing and regulation of expression," Antioxidants and Redox Signaling, vol. 9, no. 12, pp. 2209-2225, 2007.

[25] S. W. Ryter and A. M. K. Choi, "Heme oxygenase-1/carbon monoxide: novel therapeutic strategies in critical care medicine," Current Drug Targets, vol. 11, no. 12, pp. 14851494, 2010.

[26] A. Jazwa and A. Cuadrado, "Targeting heme oxygenase-1 for neuroprotection and neuroinflammation in neurodegenerative diseases," Current Drug Targets, vol. 11, no. 12, pp. 1517-1531, 2010.

[27] M. Wu, Y. Ho, and S. Yet, "A central role of heme oxygenase-1 in cardiovascular protection," Antioxidants and Redox Signaling, vol. 15, no. 7, pp. 1835-1846, 2011.

[28] A. Agarwal and S. Bolisetty, "Adaptive responses to tissue injury: role of heme oxygenase-1," Transactions of the American Clinical and Climatological Association, vol. 124, pp. 111-122, 2013.
[29] M. Hæger, M. Unander, B. Andersson, A. Tarkowski, J. P. Arnestad, and A. Bengtsson, "Increased release of tumor necrosis factor-alpha and interleukin-6 in women with the syndrome of hemolysis, elevated liver enzymes, and low platelet count," Acta Obstetricia et Gynecologica Scandinavica, vol. 75, no. 8, pp. 695701, 1996.

[30] M. A. Arruda, A. G. Rossi, M. S. de Freitas, C. Barja-Fidalgo, and A. V. Graça-Souza, "Heme inhibits human neutrophil apoptosis: involvement of phosphoinositide 3-kinase, MAPK, and NF- $\kappa \mathrm{B}$," The Journal of Immunology, vol. 173, no. 3, pp. 2023-2030, 2004.

[31] M. J. Tracz, J. Alam, and K. A. Nath, "Physiology and pathophysiology of heme: implications for kidney disease," Journal of the American Society of Nephrology, vol. 18, no. 2, pp. 414-420, 2007.

[32] B. Halliwell and J. M. C. Gutteridge, "Oxygen toxicity, oxygen radicals, transition metals and disease," Biochemical Journal, vol. 219, no. 1, pp. 1-14, 1984.

[33] J. D. Belcher, J. D. Beckman, G. Balla, J. Balla, and G. Vercellotti, "Heme degradation and vascular injury," Antioxidants and Redox Signaling, vol. 12, no. 2, pp. 233-248, 2010.

[34] C. Mancuso and E. Barone, "The heme oxygenase/biliverdin reductase pathway in drug research and development," Current Drug Metabolism, vol. 10, no. 6, pp. 579-594, 2009.

[35] R. M. Davydov, T. Yoshida, M. Ikeda-Saito, and B. M. Hoffman, "Hydroperoxy-heme oxygenase generated by cryoreduction catalyzes the formation of $\alpha$-meso-hydroxyheme as detected by EPR and ENDOR," Journal of the American Chemical Society, vol. 121, no. 45, pp. 10656-10657, 1999.

[36] X. Zhang, H. Fujii, K. Mansfield Matera et al., "Stereoselectivity of each of the three steps of the heme oxygenase reaction: hemin to meso-hydroxyhemin, meso-hydroxyhemin to verdoheme, and verdoheme to biliverdin," Biochemistry, vol. 42, no. 24, pp. 7418-7426, 2003.

[37] Y. Zhu and R. B. Silverman, "Revisiting heme mechanisms. A perspective on the mechanisms of nitric oxide synthase (NOS), heme oxygenase (HO), and cytochrome P450s (CYP450s)," Biochemistry, vol. 47, no. 8, pp. 2231-2243, 2008.

[38] L. E. Otterbein, F. H. Bach, J. Alam et al., "Carbon monoxide has anti-inflammatory effects involving the mitogen-activated protein kinase pathway," Nature Medicine, vol. 6, no. 4, pp. 422428, 2000.

[39] G. Sass, M. C. P. Soares, K. Yamashita et al., "Heme oxygenase- 1 and its reaction product, carbon monoxide, prevent inflammation-related apoptotic liver damage in mice," Hepatology, vol. 38, no. 4, pp. 909-918, 2003.

[40] S. W. Ryter and L. E. Otterbein, "Carbon monoxide in biology and medicine," BioEssays, vol. 26, no. 3, pp. 270-280, 2004.

[41] T. W. Sedlak and S. H. Snyder, "Bilirubin benefits: cellular protection by a biliverdin reductase antioxidant cycle," Pediatrics, vol. 113, no. 6, pp. 1776-1782, 2004.

[42] D. E. Barañano, M. Rao, C. D. Ferris, and S. H. Snyder, "Biliverdin reductase: a major physiologic cytoprotectant," Proceedings of the National Academy of Sciences of the United States of America, vol. 99, no. 25, pp. 16093-16098, 2002.

[43] J. Y. Kwak, K. Takeshige, B. S. Cheung, and S. Minakami, “Bilirubin inhibits the activation of superoxide-producing $\mathrm{NADPH}$ oxidase in a neutrophil cell-free system," Biochimica et Biophysica Acta, vol. 1076, no. 3, pp. 369-373, 1991.

[44] C. L. Basiglio, S. M. Arriaga, F. Pelusa, A. M. Almará, J. Kapitulnik, and A. D. Mottino, "Complement activation and disease: 
protective effects of hyperbilirubinaemia," Clinical Science, vol. 118, no. 2, pp. 99-113, 2010.

[45] Y. Haga, M. A. Tempero, and R. K. Zetterman, "Unconjugated bilirubin inhibits in vitro major histocompatibility complexunrestricted cytotoxicity of human lymphocytes," Biochimica et Biophysica Acta-Molecular Basis of Disease, vol. 1316, no. 1, pp. 29-34, 1996.

[46] C. Thorup, C. L. Jones, S. S. Gross, L. C. Moore, and M. S. Goligorsky, "Carbon monoxide induces vasodilation and nitric oxide release but suppresses endothelial NOS," The American Journal of Physiology, vol. 277, no. 6, part 2, pp. F882-F889, 1999.

[47] T. Morita, S. A. Mitsialis, H. Koike, Y. Liu, and S. Kourembanas, "Carbon monoxide controls the proliferation of hypoxic vascular smooth muscle cells," Journal of Biological Chemistry, vol. 272, no. 52, pp. 32804-32809, 1997.

[48] C. Taillé, J. El-Benna, S. Lanone, J. Boczkowski, and R. Motterlini, "Mitochondrial respiratory chain and $\mathrm{NAD}(\mathrm{P}) \mathrm{H}$ oxidase are targets for the antiproliferative effect of carbon monoxide in human airway smooth muscle," Journal of Biological Chemistry, vol. 280, no. 27, pp. 25350-25360, 2005.

[49] H. P. Kim, S. W. Ryter, and A. M. Choi, "CO as a cellular signaling molecule," Annual Review of Pharmacology and Toxicology, vol. 46, pp. 411-449, 2006.

[50] D. Morse, J. Sethi, and A. M. K. Choi, "Carbon monoxidedependent signaling," Critical Care Medicine, vol. 30, no. 1, pp. S12-S17, 2002.

[51] B. Y. Chin, G. Jiang, B. Wegiel et al., "Hypoxia-inducible factor $1 \alpha$ stabilization by carbon monoxide results in cytoprotective preconditioning," Proceedings of the National Academy of Sciences of the United States of America, vol. 104, no. 12, pp. 5109$5114,2007$.

[52] Y. K. Choi, E. D. Por, Y.-G. Kwon, and Y.-M. Kim, "Regulation of ROS production and vascular function by carbon monoxide," Oxidative Medicine and Cellular Longevity, vol. 2012, Article ID 794237, 17 pages, 2012.

[53] S. W. Ryter and R. M. Tyrrell, "The heme synthesis and degradation pathways: role in oxidant sensitivityHeme oxygenase has both pro- and antioxidant properties," Free Radical Biology and Medicine, vol. 28, no. 2, pp. 289-309, 2000.

[54] Y. M. Kim, H. T. Chung, R. L. Simmons, and T. R. Billiar, "Cellular non-heme iron content is a determinant of nitric oxide-mediated apoptosis, necrosis, and caspase inhibition," The Journal of Biological Chemistry, vol. 275, no. 15, pp. 1095410961, 2000.

[55] Y. Kim, B. Choi, Y. Kim et al., "Protective effect of p53 in vascular smooth muscle cells against nitric oxide-induced apoptosis is mediated by up-regulation of heme oxygenase-2," Journal of Biochemistry and Molecular Biology, vol. 41, no. 2, pp. 164-169, 2008.

[56] M. D. Maines and A. Kappas, "Cobalt induction of hepatic heme oxygenase; with evidence that cytochrome P-450 is not essential for this enzyme activity," Proceedings of the National Academy of Sciences of the United States of America, vol. 71, no. 11, pp. 42934297, 1974.

[57] T. Yoshida, S. Takahashi, and G. Kikuchi, "Partial purification and reconstitution of the heme oxygenase system from pig spleen microsomes," The Journal of Biochemistry, vol. 75, no. 5, pp. 1187-1191, 1974

[58] M. D. Maines, G. M. Trakshel, and R. K. Kutty, "Characterization of two constitutive forms of rat liver microsomal heme oxygenase: only one molecular species of the enzyme is inducible," Journal of Biological Chemistry, vol. 261, no. 1, pp. 411-419, 1986.

[59] G. M. Trakshel, R. K. Kutty, and M. D. Maines, "Purification and characterization of the major constitutive form of testicular heme oxygenase: the non-inducible isoform," Journal of Biological Chemistry, vol. 261, no. 24, pp. 11131-11137, 1986.

[60] W. K. Mccoubrey Jr., T. J. Huang, and M. D. Maines, "Isolation and characterization of a cDNA from the rat brain that encodes hemoprotein heme oxygenase-3," European Journal of Biochemistry, vol. 247, no. 2, pp. 725-732, 1997.

[61] S. Hayashi, Y. Omata, H. Sakamoto et al., "Characterization of rat heme oxygenase-3 gene: implication of processed pseudogenes derived from heme oxygenase-2 gene," Gene, vol. 336, no. 2, pp. 241-250, 2004.

[62] F. A. Wagener, J. da Silva, T. Farley, T. de Witte, A. Kappas, and N. G. Abraham, "Differential effects of heme oxygenase isoforms on heme mediation of endothelial intracellular adhesion molecule expression," Journal of Pharmacology and Experimental Therapeutics, vol. 291, no. 1, pp. 416-423, 1999.

[63] W. K. McCoubrey Jr. and M. D. Maines, "The structure, organization and differential expression of the gene encoding rat heme oxygenase-2," Gene, vol. 139, no. 2, pp. 155-161, 1994.

[64] W. K. McCoubrey Jr., B. Eke, and M. D. Maines, "Multiple transcripts encoding heme oxygenase- 2 in rat testis: developmental and cell-specific regulation of transcripts and protein," Biology of Reproduction, vol. 53, no. 6, pp. 1330-1338, 1995.

[65] W. K. McCoubrey Jr., J. F. Ewing, and M. D. Maines, "Human heme oxygenase-2: characterization and expression of a fulllength cDNA and evidence suggesting that the two HO-2 transcripts may differ by choice of polyadenylation signal," Archives of Biochemistry and Biophysics, vol. 295, no. 1, pp. 1320, 1992.

[66] C. M. Bianchetti, L. Yi, S. W. Ragsdale, and G. N. Phillips Jr., "Comparison of apo- and heme-bound crystal structures of a truncated human heme oxygenase-2," The Journal of Biological Chemistry, vol. 282, no. 52, pp. 37624-37631, 2007.

[67] D. J. Schuller, A. Wilks, P. R. Ortiz de Montellano, and T. L. Poulos, "Crystal structure of human heme oxygenase-1," Nature Structural Biology, vol. 6, no. 9, pp. 860-867, 1999.

[68] S. W. Ragsdale and L. Yi, "Thiol/disulfide redox switches in the regulation of heme binding to proteins," Antioxidants and Redox Signaling, vol. 14, no. 6, pp. 1039-1047, 2011.

[69] L. Yi and S. W. Ragsdale, "Evidence that the heme regulatory motifs in heme oxygenase-2 serve as a thiol/disulfide redox switch regulating heme binding," The Journal of Biological Chemistry, vol. 282, no. 29, pp. 21056-21067, 2007.

[70] S. E. J. Williams, P. Wootton, H. S. Mason et al., "Hemoxygenase-2 is an oxygen sensor for a calcium-sensitive potassium channel," Science, vol. 306, no. 5704, pp. 2093-2097, 2004.

[71] R. K. Kutty, G. Kutty, I. R. Rodriquez, G. J. Chader, and B. Wiggert, "Chromosomal localization of the human heme oxygenase genes: Heme oxygenase-1 (HMOX1) maps to chromosome 22q12 and heme oxygenase-2 (HMOX2) maps to chromosome 16p13.3," Genomics, vol. 20, no. 3, pp. 513-516, 1994.

[72] R. M. Müller, H. Taguchi, and S. Shibahara, "Nucleotide sequence and organization of the rat heme oxygenase gene," Journal of Biological Chemistry, vol. 262, no. 14, pp. 6795-6802, 1987.

[73] Y. Sun, M. O. Rotenberg, and M. D. Maines, "Developmental expression of heme oxygenase isozymes in rat brain: two $\mathrm{HO}-2$ mRNAs are detected," The Journal of Biological Chemistry, vol. 265, no. 14, pp. 8212-8217, 1990. 
[74] L. Gibbs, D. Willis, and M. J. Morgan, “The identification and expression of heme oxygenase- 2 alternative transcripts in the mouse," Gene, vol. 221, no. 2, pp. 171-177, 1998.

[75] G. M. Trakshel, J. F. Ewing, and M. D. Maines, "Heterogeneity of haem oxygenase 1 and 2 isoenzymes. Rat and primate transcripts for isoenzyme 2 differ in number and size," Biochemical Journal, vol. 275, part 1, pp. 159-164, 1991.

[76] S. Immenschuh and G. Ramadori, "Gene regulation of heme oxygenase-1 as a therapeutic target," Biochemical Pharmacology, vol. 60 , no. 8, pp. 1121-1128, 2000.

[77] J. Alam and J. L. Cook, "How many transcription factors does it take to turn on the heme oxygenase-1 gene?" American Journal of Respiratory Cell and Molecular Biology, vol. 36, no. 2, pp. 166174, 2007.

[78] Y. Shan, R. W. Lambrecht, T. Ghaziani, S. E. Donohue, and H. L. Bonkovsky, "Role of Bach-1 in regulation of heme oxygenase-1 in human liver cells: insights from studies with small interfering RNAs," The Journal of Biological Chemistry, vol. 279, no. 50, pp. 51769-51774, 2004.

[79] T. D. Hock, K. Liby, M. M. Wright et al., "JunB and JunD regulate human heme oxygenase-1 gene expression in renal epithelial cells," The Journal of Biological Chemistry, vol. 282, no. 9, pp. 6875-6886, 2007.

[80] V. S. Raju, W. K. McCoubrey Jr., and M. D. Maines, "Regulation of heme oxygenase- 2 by glucocorticoids in neonatal rat brain: characterization of a functional glucocorticoid response element," Biochimica et Biophysica Acta: Gene Structure and Expression, vol. 1351, no. 1-2, pp. 89-104, 1997.

[81] M. D. Maines, B. C. Eke, and X. Zhao, "Corticosterone promotes increased heme oxygenase-2 protein and transcript expression in the newborn rat brain," Brain Research, vol. 722, no. 1-2, pp. 83-94, 1996.

[82] N. Liu, X. Wang, W. K. McCoubrey Jr., and M. D. Maines, "Developmentally regulated expression of two transcripts for heme oxygenase- 2 with a first exon unique to rat testis: control by corticosterone of the oxygenase protein expression," Gene, vol. 241, no. 1, pp. 175-183, 2000.

[83] M. Sugishima, Y. Hagiwara, X. Zhang, T. Yoshida, C. T. Migita, and K. Fukuyama, "Crystal structure of dimeric heme oxygenase-2 from Synechocystis sp. PCC 6803 in complex with heme," Biochemistry, vol. 44, no. 11, pp. 4257-4266, 2005.

[84] Q. Lin, S. Weis, G. Yang et al., "Heme oxygenase-1 protein localizes to the nucleus and activates transcription factors important in oxidative stress," The Journal of Biological Chemistry, vol. 282, no. 28, pp. 20621-20633, 2007.

[85] M. Linnenbaum, M. Busker, J. R. Kraehling, and S. Behrends, "Heme oxygenase isoforms differ in their subcellular trafficking during hypoxia and are differentially modulated by cytochrome P450 reductase," PLoS ONE, vol. 7, no. 4, Article ID e35483, 2012.

[86] W. K. McCoubrey Jr. and M. D. Maines, "Domains of rat heme oxygenase-2: the amino terminus and histidine 151 are required for heme oxidation," Archives of Biochemistry and Biophysics, vol. 302, no. 2, pp. 402-408, 1993.

[87] A. Wilks, P. R. Ortiz De Montellano, J. Sun, and T. M. Loehr, "Heme oxygenase (HO-1): His-132 stabilizes a distal water ligand and assists catalysis," Biochemistry, vol. 35, no. 3, pp. 930936, 1996.

[88] L. Lad, D. J. Schuller, H. Shimizu et al., "Comparison of the heme-free and -bound crystal structures of human heme oxygenase-1," The Journal of Biological Chemistry, vol. 278, no. 10, pp. 7834-7843, 2003.
[89] W. K. McCoubrey Jr., T. J. Huang, and M. D. Maines, "Heme oxygenase- 2 is a hemoprotein and binds heme through heme regulatory motifs that are not involved in heme catalysis," Journal of Biological Chemistry, vol. 272, no. 19, pp. 12568-12574, 1997.

[90] T. Hon, A. Hach, H. C. Lee, T. Cheng, and L. Zhang, "Functional analysis of heme regulatory elements of the transcriptional activator Hap1," Biochemical and Biophysical Research Communications, vol. 273, no. 2, pp. 584-591, 2000.

[91] H. C. Lee, T. Hon, C. Lan, and L. Zhang, "Structural environment dictates the biological significance of heme-responsive motifs and the role of Hsp90 in the activation of the heme activator protein Hap1," Molecular and Cellular Biology, vol. 23, no. 16, pp. 5857-5866, 2003.

[92] J. Yang, K. Ishimori, and M. R. O'Brian, “Two heme binding sites are involved in the regulated degradation of the bacterial iron response regulator (Irr) protein," The Journal of Biological Chemistry, vol. 280, no. 9, pp. 7671-7676, 2005.

[93] T. J. Huang, W. K. McCoubrey Jr., and M. D. Maines, "Heme oxygenase-2 interaction with metalloporphyrins: function of heme regulatory motifs," Antioxidants and Redox Signaling, vol. 3, no. 4, pp. 685-696, 2001.

[94] L. Yi, P. M. Jenkins, L. I. Leichert, U. Jakob, J. R. Martens, and S. W. Ragsdale, "Heme regulatory motifs in heme oxygenase-2 form a thiol/disulfide redox switch that responds to the cellular redox state," Journal of Biological Chemistry, vol. 284, no. 31, pp. 20556-20561, 2009.

[95] F. Varfaj, J. N. Lampe, and P. R. O. De Montellano, "Role of cysteine residues in heme binding to human heme oxygenase-2 elucidated by two-dimensional NMR spectroscopy," The Journal of Biological Chemistry, vol. 287, no. 42, pp. 35181-35191, 2012.

[96] B. K. May, C. R. Bhasker, M. J. Bawden, and T. C. Cox, "Molecular regulation of 5-aminolevulinate synthase. Diseases related to heme biosynthesis," Molecular Biology and Medicine, vol. 7, no. 5, pp. 405-421, 1990.

[97] D. Boehning, C. Moon, S. Sharma et al., "Carbon monoxide neurotransmission activated by CK2 phosphorylation of heme oxygenase-2," Neuron, vol. 40, no. 1, pp. 129-137, 2003.

[98] D. Boehning, L. Sedaghat, T. W. Sedlak, and S. H. Snyder, "Heme oxygenase- 2 is activated by calcium-calmodulin," Journal of Biological Chemistry, vol. 279, no. 30, pp. 30927-30930, 2004.

[99] Q. Xi, D. Tcheranova, S. Basuroy, H. Parfenova, J. H. Jaggar, and C. W. Leffler, "Glutamate-induced calcium signals stimulate CO production in piglet astrocytes," The American Journal of Physiology - Heart and Circulatory Physiology, vol. 301, no. 2, pp. H428-H433, 2011.

[100] C. W. Leffler, L. Balabanova, C. D. Sullivan, X. Wang, A. L. Fedinec, and H. Parfenova, "Regulation of CO production in cerebral microvessels of newborn pigs," The American Journal of Physiology-Heart and Circulatory Physiology, vol. 285, no. 1, pp. H292-H297, 2003.

[101] Y. Ding, W. K. McCoubrey Jr., and M. D. Maines, "Interaction of heme oxygenase- 2 with nitric oxide donors. Is the oxygenase an intracellular 'sink' for NO?" European Journal of Biochemistry, vol. 264, no. 3, pp. 854-861, 1999.

[102] C. W. Leffler, L. Balabanova, A. L. Fedinec, and H. Parfenova, "Nitric oxide increases carbon monoxide production by piglet cerebral microvessels," The American Journal of PhysiologyHeart and Circulatory Physiology, vol. 289, no. 4, pp. H1442H1447, 2005.

[103] S. Basuroy, D. Tcheranova, S. Bhattacharya, C. W. Leffler, and H. Parfenova, "Nox4 NADPH oxidase-derived reactive oxygen 
species, via endogenous carbon monoxide, promote survival of brain endothelial cells during TNF- $\alpha$-induced apoptosis," The American Journal of Physiology - Cell Physiology, vol. 300, no. 2, pp. C256-C265, 2011.

[104] D. Vukomanovic, B. E. McLaughlin, M. N. Rahman et al., "Selective activation of heme oxygenase- 2 by menadione," Canadian Journal of Physiology and Pharmacology, vol. 89, no. 11, pp. 861-864, 2011.

[105] Y. Kim and S. Doré, "Catalytically inactive heme oxygenase-2 mutant is cytoprotective," Free Radical Biology and Medicine, vol. 39, no. 4, pp. 558-564, 2005.

[106] Y. Weng, G. Yang, S. Weiss, and P. A. Dennery, "Interaction between heme oxygenase-1 and -2 proteins," Journal of Biological Chemistry, vol. 278, no. 51, pp. 50999-51005, 2003.

[107] H. J. Vreman, B. C. Ekstrand, and D. K. Stevenson, "Selection of metalloporphyrin heme oxygenase inhibitors based on potency and photoreactivity," Pediatric Research, vol. 33, no. 2, pp. 195200, 1993.

[108] R. T. Kinobe, J. Z. Vlahakis, H. J. Vreman et al., "Selectivity of imidazole-dioxolane compounds for in vitro inhibition of microsomal haem oxygenase isoforms," The British Journal of Pharmacology, vol. 147, no. 3, pp. 307-315, 2006.

[109] J. Z. Vlahakis, R. T. Kinobe, R. J. Bowers, J. F. Brien, K. Nakatsu, and W. A. Szarek, "Imidazole-dioxolane compounds as isozyme-selective heme oxygenase inhibitors," Journal of Medicinal Chemistry, vol. 49, no. 14, pp. 4437-4441, 2006.

[110] M. N. Rahman, D. Vukomanovic, J. Z. Vlahakis, W. A. Szarek, K. Nakatsu, and Z. Jia, "Structural insights into human heme oxygenase-1 inhibition by potent and selective azole-based compounds," Journal of the Royal Society Interface, vol. 10, no. 78, Article ID 20120697, 2013.

[111] J. F. Ewing and M. D. Maines, "Rapid induction of heme oxygenase $1 \mathrm{mRNA}$ and protein by hyperthermia in rat brain: heme oxygenase 2 is not a heat shock protein," Proceedings of the National Academy of Sciences of the United States of America, vol. 88, no. 12, pp. 5364-5368, 1991.

[112] J. F. Ewing, S. N. Haber, and M. D. Maines, "Normal and heatinduced patterns of expression of heme oxygenase-1 (HSP32) in rat brain: hyperthermia causes rapid induction of mRNA and protein," Journal of Neurochemistry, vol. 58, no. 3, pp. 1140-1149, 1992.

[113] B. E. Dwyer, R. N. Nishimura, and S. Lu, "Differential expression of heme oxygenase-1 in cultured cortical neurons and astrocytes determined by the aid of a new heme oxygenase antibody. Response to oxidative stress," Molecular Brain Research, vol. 30, no. 1, pp. 37-47, 1995.

[114] R. F. Regan, Y. Guo, and N. Kumar, "Heme oxygenase-1 induction protects murine cortical astrocytes from hemoglobin toxicity," Neuroscience Letters, vol. 282, no. 1-2, pp. 1-4, 2000.

[115] H. Parfenova and C. W. Leffler, "Cerebroprotective functions of HO-2," Current Pharmaceutical Design, vol. 14, no. 5, pp. 443453, 2008.

[116] J. Wang, H. Zhuang, and S. Doré, "Heme oxygenase 2 is neuroprotective against intracerebral hemorrhage," Neurobiology of Disease, vol. 22, no. 3, pp. 473-476, 2006.

[117] E. F. Chang, R. J. Wong, H. J. Vreman et al., "Heme oxygenase2 protects against lipid peroxidation-mediated cell loss and impaired motor recovery after traumatic brain injury," Journal of Neuroscience, vol. 23, no. 9, pp. 3689-3696, 2003.

[118] S. Basuroy, S. Bhattacharya, D. Tcheranova et al., "HO-2 provides endogenous protection against oxidative stress and apoptosis caused by TNF- $\alpha$ in cerebral vascular endothelial cells," American Journal of Physiology-Cell Physiology, vol. 291, no. 5, pp. C897-C908, 2006.

[119] F. Seta, L. Bellner, R. Rezzani et al., "Heme oxygenase-2 is a critical determinant for execution of an acute inflammatory and reparative response," The American Journal of Pathology, vol. 169, no. 5, pp. 1612-1623, 2006.

[120] L. Bellner, L. Martinelli, A. Halilovic et al., "Heme oxygenase-2 deletion causes endothelial cell activation marked by oxidative stress, inflammation, and angiogenesis," Journal of Pharmacology and Experimental Therapeutics, vol. 331, no. 3, pp. 925-932, 2009.

[121] S. Turkseven, G. Drummond, R. Rezzani et al., "Impact of silencing HO-2 on EC-SOD and the mitochondrial signaling pathway," Journal of Cellular Biochemistry, vol. 100, no. 4, pp. 815-823, 2007.

[122] B. Ding, P. E. M. Gibbs, P. S. Brookes, and M. D. Maines, "The coordinated increased expression of biliverdin reductase and heme oxygenase- 2 promotes cardiomyocyte survival: a reductase-based peptide counters $\beta$-adrenergic receptor ligandmediated cardiac dysfunction," The FASEB Journal, vol. 25, no. 1, pp. 301-313, 2011.

[123] D. Liang and J. D. Clark, "Modulation of the NO/CO-cGMP signaling cascade during chronic morphine exposure in mice," Neuroscience Letters, vol. 365, no. 1, pp. 73-77, 2004.

[124] B. Li, K. Takeda, K. Ishikawa et al., "Coordinated expression of 6-phosphofructo-2-kinase/ fructose-2,6-bisphosphatase 4 and heme oxygenase 2: evidence for a regulatory link between glycolysis and heme catabolism," Tohoku Journal of Experimental Medicine, vol. 228, no. 1, pp. 27-41, 2012.

[125] L.-H. Sylvia, L. Jih-Jing, K. Hsiang-Fu, P. L. Huang, L. Leo, and P. L. Huang, "The 3 ' flanking region of the human erythropoietinencoding gene contains nitrogen-regulatory/oxygen-sensing consensus sequences and tissue-specific transcriptional regulatory elements," Gene, vol. 137, no. 2, pp. 203-210, 1993.

[126] C. Eyzaguirre and P. Zapata, "The release of acetylcholine from carotid body tissues. Further study on the effects of acetylcholine and cholinergic blocking agents on the chemosensory discharge," Journal of Physiology, vol. 195, no. 3, pp. 589-607, 1968.

[127] S. Fidone, C. Gonzalez, and K. Yoshizaki, "Effects of low oxygen on the release of dopamine from the rabbit carotid body in vitro," The Journal of Physiology, vol. 333, pp. 93-110, 1982.

[128] R. Rigual, E. Gonzalez, C. Gonzalez, and S. Fidone, "Synthesis and release of catecholamines by the cat carotid body in vitro: effects of hypoxic stimulation," Brain Research, vol. 374, no. 1, pp. 101-109, 1986.

[129] M. Zhang, H. Zhong, C. Vollmer, and C. A. Nurse, "Co-release of ATP and ACh mediates hypoxic signalling at rat carotid body chemoreceptors," Journal of Physiology, vol. 525, no. 1, part 1, pp. 143-158, 2000.

[130] I. Vicario, R. Rigual, A. Obeso, and C. Gonzalez, "Characterization of the synthesis and release of catecholamine in the rat carotid body in vitro," The American Journal of Physiology-Cell Physiology, vol. 278, no. 3, pp. C490-C499, 2000.

[131] H. J. L. M. Timmers, W. Wieling, J. M. Karemaker, and J. W. M. Lenders, "Denervation of carotid baro- and chemoreceptors in humans," The Journal of Physiology, vol. 553, part 1, pp. 3-11, 2003.

[132] B. A. Williams and K. J. Buckler, "Biophysical properties and metabolic regulation of a TASK-like potassium channel in rat 
carotid body type 1 cells," The American Journal of Physiology: Lung Cellular and Molecular Physiology, vol. 286, no. 1, pp. L221L230, 2004.

[133] A. Lewis, C. Peers, M. L. J. Ashford, and P. J. Kemp, "Hypoxia inhibits human recombinant maxi $\mathrm{K}^{+}$channels by a mechanism which is membrane delimited and $\mathrm{Ca}^{2+}$-sensitive," The Journal of Physiology, vol. 540, part 3, pp. 771-780, 2002.

[134] J. Cui, H. Yang, and U. S. Lee, "Molecular mechanisms of BK channel activation," Cellular and Molecular Life Sciences, vol. 66, no. 5, pp. 852-875, 2009.

[135] X. D. Tang, R. Xu, M. F. Reynolds, M. L. Garcia, S. H. Heinemann, and T. Hoshi, "Haem can bind to and inhibit mammalian calcium-dependent Slo1 BK channels," Nature, vol. 425, no. 6957, pp. 531-535, 2003.

[136] S. Hou, R. Xu, S. H. Heinemann, and T. Hoshi, "Reciprocal regulation of the $\mathrm{Ca}^{2+}$ and $\mathrm{H}^{+}$sensitivity in the SLO1 BK channel conferred by the RCK1 domain," Nature Structural and Molecular Biology, vol. 15, no. 4, pp. 403-410, 2008.

[137] L. Yi, J. T. Morgan, and S. W. Ragsdale, "Identification of a thiol/disulfide redox switch in the human BK channel that controls its affinity for heme and CO," Journal of Biological Chemistry, vol. 285, no. 26, pp. 20117-20127, 2010.

[138] A. M. Riesco-Fagundo, M. T. Pérez-García, C. González, and J. R. López-López, “ $\mathrm{O}_{2}$ modulates large-conductance $\mathrm{Ca}^{2+}$ dependent $\mathrm{K}^{+}$channels of rat chemoreceptor cells by a membrane-restricted and CO-sensitive mechanism," Circulation Research, vol. 89, no. 5, pp. 430-436, 2001.

[139] N. R. Prabhakar, "NO and CO as second messengers in oxygen sensing in the carotid body," Respiration Physiology, vol. 115, no. 2, pp. 161-168, 1999.

[140] P. J. Kemp, "Hemeoxygenase- 2 as an $\mathrm{O}_{2}$ sensor in $\mathrm{K}^{+}$channeldependent chemotransduction," Biochemical and Biophysical Research Communications, vol. 338, no. 1, pp. 648-652, 2005.

[141] F. Han, K. Takeda, M. Ono et al., "Hypoxemia induces expression of heme oxygenase-1 and heme oxygenase- 2 proteins in the mouse myocardium," Journal of Biochemistry, vol. 147, no. 1, pp. 143-151, 2010.

[142] D. Newby, F. Cousins, L. Myatt, and F. Lyall, "Heme oxygenase expression in cultured human trophoblast cells during in vitro differentiation: effects of hypoxia," Placenta, vol. 26, no. 2-3, pp. 201-209, 2005.

[143] V. Govindaraju, H. Teoh, Q. Hamid, P. Cernacek, and M. E. Ward, "Interaction between endothelial heme oxygenase-2 and endothelin-1 in altered aortic reactivity after hypoxia in rats," The American Journal of Physiology-Heart and Circulatory Physiology, vol. 288, no. 2, pp. H962-H970, 2005.

[144] B. A. Sutherland, R. M. A. Rahman, A. N. Clarkson, O. M. Shaw, S. M. Nair, and I. Appleton, "Cerebral heme oxygenase 1 and 2 spatial distribution is modulated following injury from hypoxia-ischemia and middle cerebral artery occlusion in rats," Neuroscience Research, vol. 65, no. 4, pp. 326-334, 2009.

[145] D. D’Agostino, E. Mazza Jr., and J. A. Neubauer, "Heme oxygenase is necessary for the excitatory response of cultured neonatal rat rostral ventrolateral medulla neurons to hypoxia," The American Journal of Physiology-Regulatory Integrative and Comparative Physiology, vol. 296, no. 1, pp. R102-R118, 2009. 


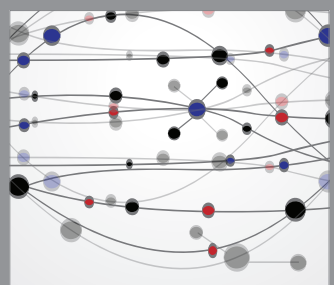

The Scientific World Journal
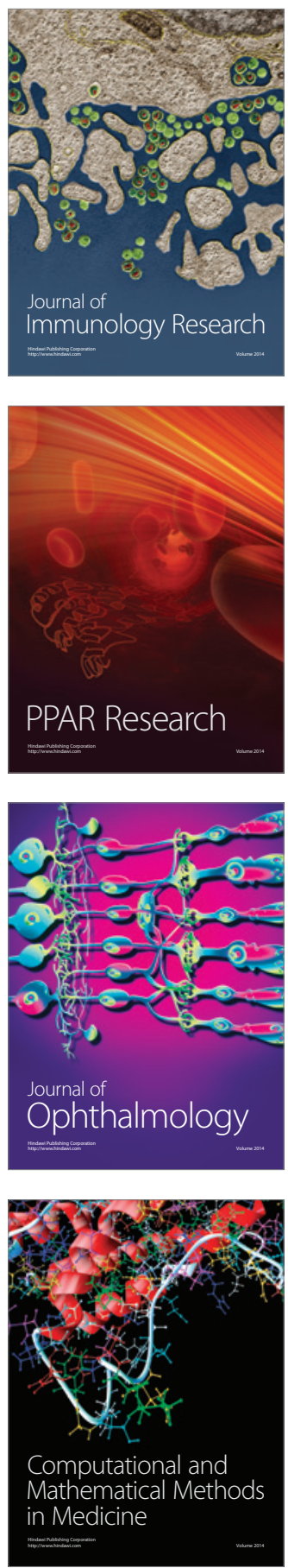

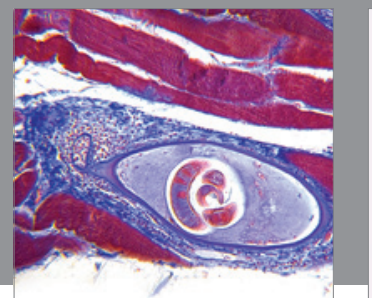

Gastroenterology

Research and Practice
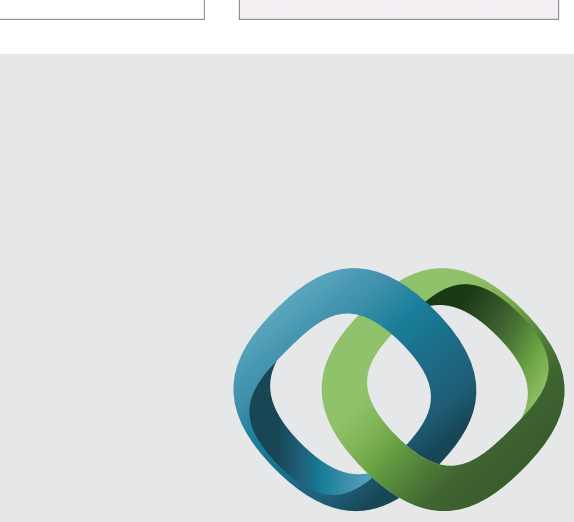

\section{Hindawi}

Submit your manuscripts at

http://www.hindawi.com
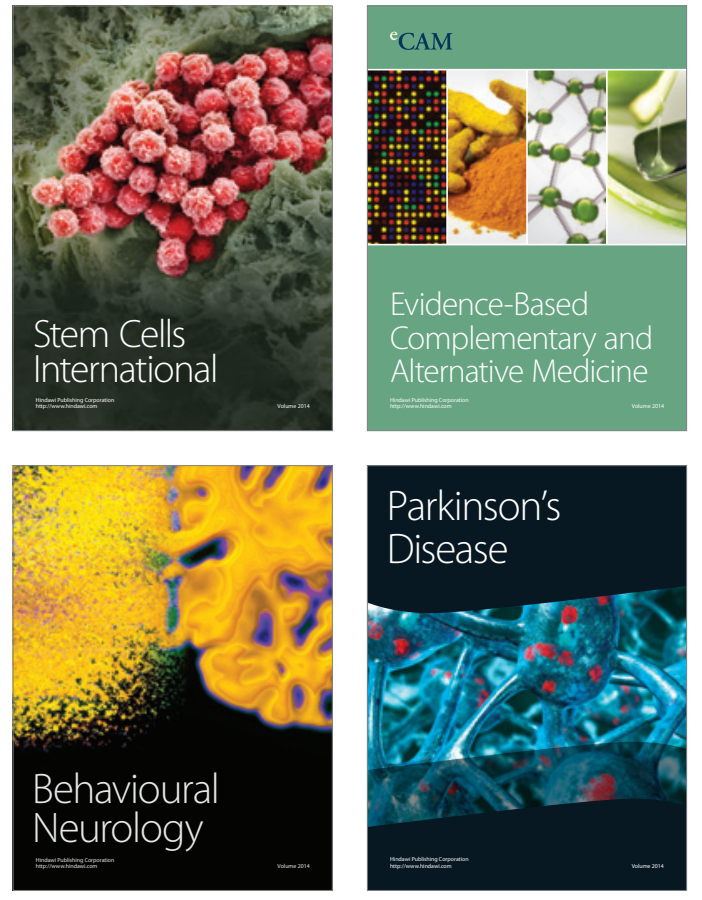
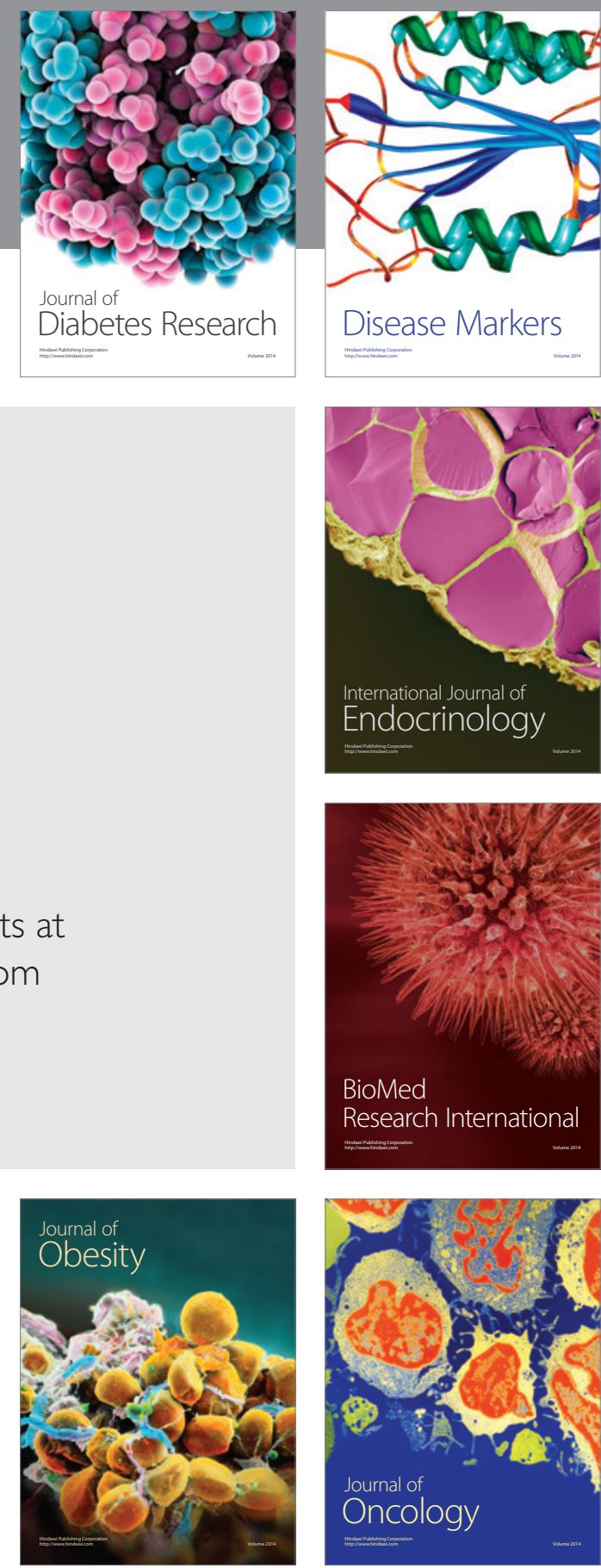

Disease Markers
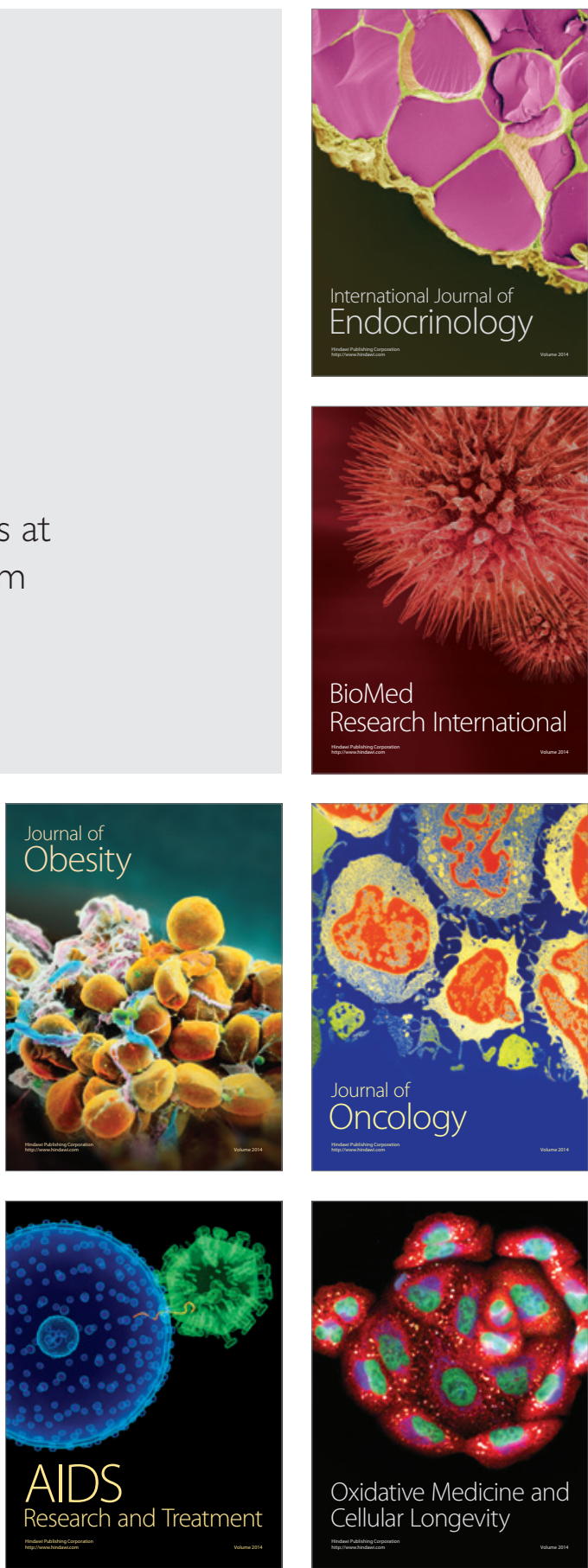